\title{
Proteins as Targets in Anti-Schistosomal Drug Discovery and Vaccine Development
}

\author{
Ndibonani Kebonang Qokoyi, Priscilla Masamba and Abidemi Paul Kappo *D \\ Molecular Biophysics and Structural Biology (MBSB) Group, Department of Biochemistry, Kingsway Campus, \\ University of Johannesburg, Auckland Park 2006, South Africa; nqoks96@gmail.com (N.K.Q.); \\ presh4u@rocketmail.com (P.M.) \\ * Correspondence: akappo@uj.ac.za; Tel.: +27-11-559-3182; Fax: +27-11-559-2605
}

check for updates

Citation: Qokoyi, N.K.; Masamba, P.; Kappo, A.P. Proteins as Targets in Anti-Schistosomal Drug Discovery and Vaccine Development. Vaccines 2021, 9, 762. https://doi.org10.3390/ vaccines $9070762 /$

Academic Editor: Chevalier Christophe

Received: 7 April 2021

Accepted: 19 May 2021

Published: 8 July 2021

Publisher's Note: MDPI stays neutral with regard to jurisdictional claims in published maps and institutional affiliations.

Copyright: (c) 2021 by the authors. Licensee MDPI, Basel, Switzerland. This article is an open access article distributed under the terms and conditions of the Creative Commons Attribution (CC BY) license (https:// creativecommons.org/licenses/by/ $4.0 /)$.

\begin{abstract}
Proteins hardly function in isolation; they form complexes with other proteins or molecules to mediate cell signaling and control cellular processes in various organisms. Protein interactions control mechanisms that lead to normal and/or disease states. The use of competitive small molecule inhibitors to disrupt disease-relevant protein-protein interactions (PPIs) holds great promise for the development of new drugs. Schistosome invasion of the human host involves a variety of cross-species protein interactions. The pathogen expresses specific proteins that not only facilitate the breach of physical and biochemical barriers present in skin, but also evade the immune system and digestion of human hemoglobin, allowing for survival in the host for years. However, only a small number of specific protein interactions between the host and parasite have been functionally characterized; thus, in-depth understanding of the molecular mechanisms of these interactions is a key component in the development of new treatment methods. Efforts are now focused on developing a schistosomiasis vaccine, as a proposed better strategy used either alone or in combination with Praziquantel to control and eliminate this disease. This review will highlight protein interactions in schistosomes that can be targeted by specific PPI inhibitors for the design of an alternative treatment to Praziquantel.
\end{abstract}

Keywords: protein-protein interactions; schistosomiasis; praziquantel; Sm-Tsp-2/Alhydrogel; SmP80/Gla-Se; Sm14/Gla-Se

\section{Introduction}

Protein-protein interactions (PPIs) have gained interest as potential drug targets for a broad range of diseases, such as tropical infections, cancer and neurological disorders, among others. Interactions between specific pairs or groups of proteins are crucial to all stages of development and homeostasis. As such, several human diseases can be traced to abnormal protein-protein interactions, either through the loss of an essential interaction or through the formation of a protein complex at an inappropriate time or location [1]. The major goal of studying PPIs in disease states is the development of novel therapies targeting interactions that are functionally relevant to disease progression and patient outcomes. Moreover, the identification of disease-specific patterns of PPIs could serve as important disease biomarkers whose selective measurement could in turn lead to improved diagnostics or prognostics for human diseases, including schistosomiasis. Human schistosomiasis is a neglected parasitic disease caused by an infection from digenetic Schistosoma trematodes and is one of the greatest threats to public health worldwide, with over 250 million reported cases of infection [2,3]. The disease is endemic in tropical areas and endemicity is dependent on the presence of the intermediate host, an aquatic snail, in freshwater bodies [4]. Estimates suggest annual deaths of over 200,000 individuals worldwide caused by the immunosuppressive and carcinogenic effects posed by infection with this disease $[5,6]$. In addition, it increases susceptibility to other harmful ailments, including hepatitis B, malaria, bladder cancer and human immunodeficiency virus (HIV) infection, which cause a 
high disease burden in schistosomiasis-endemic regions [7]. The most clinically important species are Schistosoma mansoni, which is the most common species in Africa, transmitted by Biomphalaria snails, that causes intestinal and hepatic disease; S. japonicum, transmitted by Oncomelania snails, which results in intestinal schistosomiasis in China, Indonesia and the Philippines [8]; and S. haematobium, another common African species that is transmitted by Bulinus snails and causes urogenital schistosomiasis [9].

Schistosomes have complex life cycles involving two hosts: an intermediate snail host and the definitive human host. Their development begins when eggs are released from an infected individual, either through urine or feces, and find their way to fresh water where they hatch and develop into free-swimming miracidia. The miracidium seeks and locates its intermediate host, the snail, where it reproduces and gives rise to multicellular sporocytes. These develop into cercariae (larvae), consisting of two embryonic suckers and a two-branched tail, which are capable of infecting humans [10]. To meet the World Health Organization's (WHO's) goal of eradicating the disease by 2025, alternative methods to assist the currently used drug, Praziquantel (PZQ) becomes imperative. For over 20 years, PZQ has become the most effective, common and widely used drug for the treatment of schistosomiasis due to its cost effectiveness, availability and minimal side effects on the patient. It is a pyrazine-isoquinoline derivative, first discovered in 1972, and was primarily developed for veterinary use against cestode infection [11]. It was later employed for the treatment of schistosoma infections, and since then, no therapeutic advancement has been successfully made for an alternative drug against schistosomiasis [12]. PZQ is a white crystalline powder, bitter to taste, melts at 136 to $140^{\circ} \mathrm{C}$ and is practically insoluble in water but is highly soluble in organic solvents such as chloroform and dimethylsulfoxide [13]. It is a combination of two stereoisomers, one responsible for the anti-schistosomal properties the drug possesses, while the other contributes to the minimal side effects presented by the drug and the bitter taste of the drug, making it quite difficult for small children to swallow [14]. PZQ is usually supplied as four-side shaped tablets containing $600 \mathrm{mg}$ of the active ingredient, and the recommended dose is $40-60 \mathrm{mg} / \mathrm{kg}$ body weight [15]. It has been reported that its bioavailability increases with simultaneous administration of food. About $10-60 \%$ of treated patients experience mild side effects such as dizziness, nausea, headache and sometimes vomiting. However, even in the advent of the side effects, Praziquantel has been used for mass treatment campaigns particularly targeted at school aged children, who are the most infected group of the population, due to its effectiveness against all schistosoma species infecting humans. The efficacy of PZQ is generally high, with cure rates ranging from $60 \%$ to $95 \%$; however, with PZQ being the only anti-schistosomal drug in use for more than three decades, prospects of possible drug resistance are quite high, and there have been reports of PZQ-resistant schistosomes [14,16]. Irrespective of the cases of drug resistance [17], there are other principal drawbacks associated with PZQ: it fails to destroy the worm 2-4 weeks post infection [18], it does not prevent against re-infection [11] and above all, its mechanism of action is still not yet understood [7,12]. Disruption of the lifecycle of the parasite in its infective stages is one approach that can help ease the gradual rise in Schistosoma infections [6,19]. The development of drugs and vaccines against schistosomiasis has been delayed over the years by a lack of understanding of the parasite's survival mechanisms. Schistosomes have a complex six-stage life cycle comprising several morphological stages, occurring in two distinct hosts. In this regard, schistosomes display a great capacity to survive different environmental conditions and an ability to escape the immunological responses of their respective hosts [20]. They achieve this through molecular interactions that favor their survival [21].

\subsection{Protein Composition of Schistosome Life-Cycle Stages}

\subsubsection{Eggs}

Adult worms produce eggs that are capable of restarting the infection cycle of schistosomiasis. The proteome of schistosome eggs is composed of proteins that play a defensive role in oxidative stress, such as thioredoxin and GST. In addition, triose phosphate iso- 
merase implicated in glycolysis and energy production has been shown to be highly expressed in schistosome eggs [22]. Sm40 is reportedly in high abundance in eggs and is known to play an inhibitory role in granuloma formation by minimizing potential fibrosis and cell proliferation induced by other schistosome egg proteins [23]. Additionally, calmodulin is expressed in abundance at this stage and is reported to be an essential protein for egg development. In the same vein, a polymorphic mucin variant is secreted by eggs in order to escape host immune responses by acting as a 'smoke-screen', blocking the recognition of eggs by receptors of the host defense mechanisms [22,24]. The alpha-1 glycoprotein is located in the subshell area of mature eggs, where it regulates IL-4-mediated Th2 responses, and is reported to induce a potent anti-inflammatory response by inducing regulatory $\mathrm{B}$ cells to produce IL-10 [25].

\subsubsection{Miracidia}

A highly expressed in the miracidia of S. mansoni is the S. mansoni protein 40 (Smp-40), which is reported to contribute about $15 \%$ of the soluble proteins of miracidia [26]. This protein has been studied for its role in blastogenic reactions, granuloma responses and as an immunodiagnostic target for schistosomiasis [23]. Ludolf and colleagues [27] reported that Smp-40 can be used as a potential antigen for schistosomal immunodiagnostic tests following its effective immunoprecipitation by S. mansoni chronically infected mouse serum. In addition, this protein is a member of the small heat shock protein (sHSP) family; it elicits its chaperoning function by assisting Hsp60 in capturing unfolded proteins that form stable complexes, thereby resulting in efficient disaggregation of the protein aggregates [28]. The miracidium faces a number of unfavorable physiological stresses after hatching and locating the snail host. For this reason, other members of the sHSP family upregulated at this stage include Hsp20, Hsp16, Hsp27 and Hsp40. The abundance of sHSPs is believed to provide the miracidium with protection against stress, while ensuring that glucose reserves that provide energy to the miracidia are not overused [29].

Another protein found to be highly expressed in the miracidium stage of the parasite is a $78 \mathrm{kDa}$ glucose-regulated protein (GRP78), which is a member of the heat shock protein 70 (HSP70) family. GRP78 plays a role in the folding of unfolded and partially folded proteins within the endoplasmic reticulum and is involved in the transport of secretory proteins. It is, therefore, proposed to function in a similar manner in stabilizing the macromolecular structure for miracidium proteins destined for secretion [30]. Mitochondrial import receptors are reported to be expressed in abundance in the miracidial stage and their expression may be attributed to the high energy requirement for miracidium growth, development and host-seeking activity within the first 5-6 h after hatching. Identified mitochondrial import receptors in the miracidia are TOM34 and TOM40, responsible for translocation of proteins into the mitochondria [29]. Cathepsins D and L have been identified in the proteome of miracidia; these proteases play a role as digestive enzymes in parasitic helminths [31]. The aspartic protease cathepsin D has been found in the schistosome gut as an apical enzyme that plays a significant role in the digestion of hemoglobin released from ingested erythrocytes. These two proteases might play specific roles in miracidia metabolism, including regulating digestion of the snail's hemoglobin after infection [29,32].

\subsubsection{Cercariae}

A number of proteins are expressed in the infective stage of schistosomes, which include a group of proteins involved in calcium binding, calcium regulation and calciumactivated functions. Two of these proteins paramyosin and SPO- 1 have been shown to play a role in immune evasion, while elastases are implicated in the degradation of host skin barriers. Cercarial elastase (SmCE) is the major invasive larval protease in schistosomes, secreted by the cercariae to aid mammalian host skin invasion by breaking various skin barriers [33]. An elucidation of SmCE in facilitating host penetration is exhaustively discussed later in the review. Moreover, a tegument-bound antigen, Sm14, which forms part of the fatty acid binding proteins, is found to be highly expressed during this stage of 
schistosomal development with critical roles in the uptake as well as transport of fatty acids from the host. This has also been detailed in later sections of this review. Other proteins that are abundant in the cercariae are soluble glycolytic proteins such as triose-phosphate isomerase, GAPDH and phosphoglycerate kinase, which are known to provide the energy required by the cercariae for mobility while locating a human host [34].

\subsubsection{Schistosomula}

Upon entry of the cercariae into its definitive human host, it transforms into a schistosomula which then matures into an adult worm. This stage is characterized by a drastic downregulation of the SmCE and upregulation of heat shock proteins (Hsp16, Hsp60 and Hsp70). The upregulation of HSPs in the earliest stages of intra-mammalian schistosomula development is suggested to be in response to the extensive change in niche environments, which include substantial thermal changes between freshwater and the human body $[35,36]$. A member of the tetraspanins family, Sm-TSP-2 is reported to be expressed at this stage and is responsible for tegument formation [37]. The status of this protein in vaccine development is extensively reviewed within a later section of this manuscript.

\subsubsection{Adult Worms}

Adult worms have the ability to move through different tissues within the human body, such as the liver and lungs. The fatty acid binding protein, Sm14 [38], chaperones such as Hsp60 and Hsp70 and structural proteins such as actin, tubulin, titin, paramyosin and myophilin are found to be expressed in abundance during this stage of the parasite [39]. Moreover, several cytosolic glycolytic enzymes such as enolase, pyruvate kinase and GAPDH have been found to aid in energy production in adult worms [40].

\section{Protease Inhibitors and Schistosomiasis}

Proteases are crucial for the survival of parasites, including schistosomes. A number of different proteolytic enzymes play a critical role in facilitating host invasion, nutrient uptake, hatching, evasion of the immune system and modulation of the host physiology [41]. Schistosome research has looked at cysteine (thiol) and aspartic (pepsin, cathepsin, rennin) proteases that schistosomes use as part of their survival tactics, but most attention is directed at serine proteases (trypsin/chymotrypsin-like). The most extensively studied serine protease in schistosomes is the cercarial elastase (SmCE), which is largely responsible for skin invasion by infective schistosome larvae [42]. Protease inhibitors play an important role in restraining potentially detrimental excess proteolytic activity by proteases. In accordance with the type of protease enzyme they inhibit, protease inhibitors are grouped into serine protease inhibitors (serpins, Kunitz-type, Kazal-type), cysteine protease inhibitors (cystatins), metalloproteinase inhibitors and alpha-2-macroglobulin. These inhibitors bind to the substrate to perform their function in various ways and are classified into four major categories: (i) those that block the active site of the protease (canonical inhibitors) [43]; (ii) those that bind a region adjacent to the binding site (exosite inhibitors); (3) those that bind the enzyme through a combination of canonical and exosite-binding mechanisms; (4) allosteric inhibitors that bind the enzyme in any place other than the active site [44].

\subsection{Serpins}

Proteomic analysis of $S$. mansoni larval secretions revealed a number of parasitic proteins that could potentially play a role in host immune evasion and/or promotion of parasite survival. A superfamily of macromolecular serine protease inhibitors (serpins) is one class of proteins that is proposed to function in the pathogenesis of schistosomiasis. Serpins are an ancient class of structurally conserved macromolecular inhibitors of cysteine and serine proteases that are found in nearly all biological systems, including plants, viruses, insects, prokaryotes and animals, such as members of the genus Schistosoma. In mammals, serpins play a critical role in the regulation of proteases that control blood coagulation, fibrinolytic pathways, apoptosis and inflammation [45]. All serpins 
are 330-500 amino acids long, with a molecular weight ranging from 40-60 kDa. Their structure characteristically contains three $\beta$-sheets (A, B and C), eight or nine $\alpha$-helices and a single reactive central loop (RCL). The inhibitory activity of serpins is centered on the RCL [46]. In the native form, it lies outside the main body of the serpin, between $\beta$-sheets A and C, and serves as the protease 'bait.' The RCL is composed of approximately 20 amino acid residues (P17-P4) with the P1 side chain fitting into the S1 specificity pocket of the target protease, with cleavage of the RCL occurring at the P1-P1' position. The reactive site (designated $\mathrm{P} 1$ position) in the inhibitory loop is determinant and controls much of the inhibitory activity towards the specific targeted protease. It has been proven that the presence of either Lysine or Arginine at the P1 position obstructs any protease from cleaving adjacently to those residues in the protein substrate, while the Asn13, Tyr17 and Tyr18 stabilize the canonical loop in the reactive site [47]. These features are central to the biological activity of the protein and permit the orientation of its functional moieties [48]. At the outset of interaction, the serpin binds to proteases through a non-covalent Michaelis-like complex, which is formed through interactions with residues flanking the scissile bond (P1-P1') within the RCL, forming a transient covalent ester linkage $[49,50]$. Following proteolytic cleavage, the RCL is inserted into the body of the serpin, completing the antiparallel organization of $\beta$-sheet A. The crystal structure of two trypsin (protease)$\alpha 1$-antitrypsin (serpin) reveals that once the complex forms between the protease and the serpin, translocation distorts the structure of the protease by $37 \%$, thereby reducing its ability to perform its function, while the serpin itself remains largely unchanged [51].

\subsection{Schistosome Serpins}

The function of serpins in schistosomes remains speculative, although a considerable number of serpins have been identified in the three Schistosoma species known to infect humans [34]. The phylogeny of various serpins in schistosomes has been evaluated by searching parasite databases for proteins homologous to the canonical serpin $\alpha 1$-antitrypsin, and eight complete serpin sequences have been identified in the $S$. mansoni gene database, three in the $S$. japonicum database with one partial sequence and one in the S. haematobium database (Table 1). With the exception of Sjp_0113720, alignment of the Schistosoma serpins with $\alpha 1$-antitrypsin and superimposition of the structural components of $\alpha 1$-antitrypsin indicate that these proteins contain all elements necessary for functionality [50], although their function within the worm has not been reported on. The amino acid sequence of ShSPI, Smp_090080 and Smp_090090 was reported to consist of an unusual feature for inhibitory serpins. Within the RCL of most inhibitory serpins, the P12-P9 region is characterized by amino acids with short side-chains (Ala, Gly, Ser) [52]; however, this feature is not present in these genes and this may signify a non-inhibitory function. Although most genes show over $50 \%$ similarity to known mammalian serpins, very little research has been reported in the literature on the identified serpins so far. 
Table 1. Uncharacterized Schistosome serpins.

\begin{tabular}{|c|c|c|c|c|c|}
\hline \multicolumn{6}{|c|}{ Schistosoma mansoni } \\
\hline Database Gene Name & Size $(\mathrm{kDa})$ & $\begin{array}{l}\text { Reactive Central Loop Amino } \\
\text { Acid Sequence }\end{array}$ & $\begin{array}{c}\text { Potentially Targeted } \\
\text { Protease }\end{array}$ & $\begin{array}{c}\text { Similarity to } \\
\text { Mammalian Serpin }\end{array}$ & Reference \\
\hline Smp_003300 & 43.7 & EDGVEAAAATVMGIGLRSA & $\mathrm{SmCl} 2$ & $\alpha 1$-antitrypsin (53\%) & [53] \\
\hline Smp_090080 & 46.0 & ESGIEATTVTSPIFVPISA & Elastase-2 & Neuroserpin $(48 \%)$ & {$[54]$} \\
\hline Smp_090090 & 46.3 & EVGMEARSVANAMFIPLSS & CT, Cat & Neuroserpin (52\%) & [50] \\
\hline Smp_062080 & 43.3 & EQGVVAAAASSVEVVQLSA & Cercarial elastase & SCCA-2 $(53 \%)$ & [55] \\
\hline Smp_155530 & 51.0 & EEGVVAAGVTACVFDNCDS & Peptidase complex (SPC) & SCCA-2 (55\%) & {$[50]$} \\
\hline Smp_155550 & 43.5 & EKGAVAAAATATRMIRCTA & Peptidase complex (SPC) & PAI-2 (53\%) & [50] \\
\hline Smp_155560 & 43.6 & EKGAVAAAATATQMVRCTA & Peptidase complex (SPC) & $\begin{array}{c}\text { SCCA2/SCCA1 } \\
(52 \%)\end{array}$ & [56] \\
\hline Smp_155560 & 43.8 & EKGAVAAAATATQMVRYSA & Peptidase complex (SPC) & PAI-2 (54\%) & {$[56]$} \\
\hline $\begin{array}{l}\text { Sjp_0113720 } \\
\text { Sjp_0076600 } \\
\text { Sjp_0085750 }\end{array}$ & $\begin{array}{l}26.4 \\
45.0 \\
45.6\end{array}$ & $\begin{array}{c}\text { Schistosoma } \\
\text { EKGVEAAAATAIYSLGRSL } \\
\text { EEGAVAAAASATVMLKCSA } \\
\text { ESGIEAASVTSPIIVPISA }\end{array}$ & $\begin{array}{l}\text { Thrombin } \\
\text { Peptidase complex (SPC) } \\
\text { Elastase-2 }\end{array}$ & $\begin{array}{c}\text { Ovalbumin }(52 \%) \\
\text { SerpinB6c }(57 \%) \\
\text { Neuroserpin }(50 \%)\end{array}$ & $\begin{array}{l}{[50]} \\
{[50]} \\
{[50]}\end{array}$ \\
\hline Sjp_0113080 & 43.0 & EKGAEAAAATATKIIPLSL & Cercarial elastase & $\begin{array}{l}\text { Proteinase inhibitor } 6 \\
(53 \%)\end{array}$ & {$[50]$} \\
\hline ShSPI & 45.9 & $\begin{array}{l}\text { Schistosoma ho } \\
\text { ESGIEATTVTSPIFVPFSA }\end{array}$ & $\begin{array}{l}\text { atobium } \\
\quad \text { Cercarial elastase }\end{array}$ & Ovalbumin (48\%) & [57] \\
\hline
\end{tabular}

\subsection{Functionally Characterized Schistosome Serpins}

\subsubsection{Elafin}

Skin invasion is the initial step of infection by schistosomes when the freshwaterdwelling cercariae penetrate the skin of the human host. The human skin is a formidable barrier consisting of structural proteins in the epidermis, basement membrane and extracellular matrix, which form a mechanical barrier [58]. To break this obstruction, the schistosome has to degrade the protein matrices and have the ability to minimize the immune response of the skin. Upon contact with the human host, successful cercarial penetration can be achieved within $1.5 \mathrm{~min}$, with the assistance of SmCE [4,59]. The enzyme SmCE is responsible for the degradation of skin macromolecules, including elastin, chondromucoprotein, keratin, fibronectin, laminin and collagen IV and VIII [60], to allow for the penetration of cercariae, which when inside the human host develop into mobile schistosomulae $[42,61]$. A study by Becker and co-workers reported that a serine protease inhibitor, elafin, may be a novel substrate for SmCE; it would inhibit the action of SmCE during the cercarial stage of the parasite and act as an effective barrier against infection by preventing successful penetration of the cercariae [5]. Elafin is a low molecular weight human protein that is produced naturally in the skin, lung and breast, protecting these tissues from destruction by the immune system [62]. This protein plays an important role in wound healing in the dermal immune response in humans, while also acting as an antimicrobial agent against other pathogens such as Pseudomonas aeruginosa and Staphylococcus aureus. Elafin is known to bind with high affinity to both human leukocyte elastase and porcine pancreatic elastase [63]; hence, a similar pattern on the level of affinity binding to SmCE was proposed [64]. An earlier study proposed that increased concentrations of elafin may be sufficient to act as an effective barrier against host penetration by the cercariae [65]. A similar study confirmed that applying a serine protease inhibitor to the skin prior to exposure to cercariae prevents its invasion [66]. These studies, in conjunction with the proposed role of elafin in schistosomiasis, suggest that elafin could contribute significantly to schistosomiasis-associated treatment strategies. The ability of elafin to block invasive enzymes makes it an interesting target in drug development. Its proposed interaction with the major destructive serine protease of schistosomes presents an opportunity for intense experimental validation that may provide insights into the development of a drug that can potentially prevent the onset of schistosomal infection.

\subsubsection{SmPi56}

Immunity to schistosome infection has been assigned to several immune mechanisms, including parasite opsonization by specific antibodies and a number of different effector cells, including neutrophils, macrophages and eosinophils. The mechanisms by which 
effector cells cause the death of the parasite are not well understood; however, a number of potentially toxic compounds are released by effector cells after reaching the surface of a schistosomulum and these are most likely intended to destroy the parasite. Neutrophils are reported as the first cell type of immune cells to arrive at inflammatory sites [67]. These cells play a critical role in innate immune response development in addition to their involvement in host tissue damage through secretion of proteases and cytotoxic mediators [68]. Neutrophil elastase (NE) is a critical protease in the immune response belonging to the serine protease family, which plays an important role in host defense mechanisms in both physiological and disease-associated conditions [69]. It has been reported that schistosomula and adult worms are sensitive to both pancreatic elastase and NE. To counteract the toxic effects of these proteases, schistosomes produce protease inhibitors, the best known so far being a serpin, Smpi56 [70,71]. In schistosomes, serpins have been postulated to control the homeostasis of serine proteases in the parasites themselves, as well as in their mammalian hosts [57]. SmPi56 (Schistosoma mansoni protease inhibitor, $56 \mathrm{kDa}$ ) was the first schistosome serpin to be functionally characterized from crude extracts of $S$. mansoni adult worms and was postulated to protect the schistosome from potentially damaging proteases such as NEs that are produced by the host during schistosomulae migration through various tissues in the human body [72]. This protease inhibitor is located in the tegument of adult male and female worms [57] and was found to be capable of specifically binding to pancreatic and neutrophil elastases, thereby protecting the schistosome from activated neutrophils during inflammation that could potentially kill the parasite $[50,73]$. For this reason, SmPi56-specific inhibitors that could target and block its protective role in adult worms present an interesting approach in anti-schistosomal drug development.

\subsubsection{SmSrpQ}

At multiple life cycle stages of the schistosome, the parasite moves through host tissues and breaches substantial structural barriers, including the extracellular matrix. The process of early human infection is well-characterized at the multi-cellular larval stage, where the cercariae directly penetrate host skin in a process that is largely facilitated by various secretions from a glandular network that runs the length of the larval body. These secretions contain several histolytic proteases that assist in skin penetration [66]. The larvae of $S$. mansoni invade their mammalian host with the assistance of a serine protease, $\mathrm{SmCE}$, to degrade macromolecular proteins in host skin. The catalytic activity of serine and cysteine proteases after activation is largely regulated by serpins. SmSrpQ, one of two S. mansoni serpins found in larval secretions, is only expressed during larval development and in the early stages of mammalian infection, and is responsible for regulating the activity of the major acetabular gland secretions released by skin-invading cercariae to aid in penetration [74]. It is proposed that SmSrpQ aids in protecting the parasite from its own elastase, while its tight regulation of the enzyme is also beneficial to the mammalian host, as it helps to limit host tissue damage at the site of invasion. SmSrpQ is expressed from the onset of development in daughter sporocysts until the one-day-old schistosomula stage and is not detected in either adult worms or the egg/miracidium stage. Moreover, localization of SmSrpQ to SmCE after skin penetration suggests it is unlikely that SmSrpQ interacts with SmCE within the parasite. SmSrpQ is localized in the head gland, post acetabular and a disparate set of pre-acetabular glands, whereas SmCE is found only in the adjacent set of pre-acetabular glands [74]. This suggests that SmSrpQ only plays a regulatory role in the early stages of infection when the cercariae invade host skin and enter dermal blood vessels. In addition, $\mathrm{SmSrpQ}$ does not interact with mammalian host proteases such as NE. Inhibition of the interaction between SmSrpQ and SmCE could alter the regulation of elastase production by the worm, which may have detrimental effects on the parasite itself, thereby preventing successful host penetration. Therefore, inhibitors of this protein complex may play a role in studies targeting the infective stage of schistosomes.

Z-AAPF-CMK is an effective inhibitor of cercarial invasion and a known inhibitor of SmCE [75]. It is reported that the presence of this inhibitor results in a significant reduction 
in complex formation of the SmSrpQ to SmCE complex [74,76]. This suggests that a complex between the two proteins is only formed in the presence of active SmCE, making Z-AAPF-CMK an interesting target for breaking the interaction between the two proteins, and hence, reducing the chances of protection from uncontrolled elastase production by the worm, which may potentially cause harm to the schistosome itself and potentially prevent successful transmission of the disease.

\subsubsection{SmKI-1}

Schistosomes are able to survive for prolonged periods in the blood system, in spite of continuous contact with coagulatory factors and mediators of the host immune system. Protease inhibitors play a critical role in host immune modulation, in so doing promoting parasite survival under extremely hostile environments. The Kunitz-type serine protease inhibitors are part of the serine protease inhibitor superfamily found in almost all organisms. They are generally small proteins consisting of around 60 amino acid residues and are characterized by one or more Kunitz motifs: $\alpha+\beta$ with two $\beta$ strands and two short $\alpha$ helices at the end of the domain [77]. These inhibitors have been shown to have significant physiological functions in a number of organisms. In invertebrates, Kunitz inhibitors have been known to be involved in various physiological processes, including blood coagulation, fibrinolysis, inflammation and ion channel blocking [78]. However, these proteins are not well studied in parasitic helminths and only two have been functionally characterized in schistosomes. The S. mansoni Kunitz-type protease inhibitor ( $S m \mathrm{KI}-1)$ is found in the tegument of adult worms and the sub-shell region of eggs. SmKI-1 has been shown to interact with and inhibit several proteases, including NE, which is critical in triggering immune response reactions. Morais and co-workers [67] conducted a study to evaluate the anti-inflammatory potential and the ability of SmKI-1 to interfere with neutrophil migration and function in mice infected with schistosomiasis. Treated mice developed liver damage with a significant reduction in both neutrophil accumulation and elastase activity, confirming the proposed inhibitory effect $S m \mathrm{KI}-1$ has on NE. In addition, SmKI-1 inhibits trypsin and chymotrypsin, which are serine protease digestive enzymes responsible for the degradation proteins in the small intestine. The secretion of SmKI-1 from schistosome eggs implies that it has an additional function of providing protection from these proteolytic enzymes in the gut, as many eggs pass through the intestinal wall and traverse into the gut lumen prior to being excreted in human feces to the external environment [71]. In the mesenteric veins, schistosomes release eggs into the blood, where they are exposed to host attacks, triggering the production of SmKI-1 to confer protection from the immune system [79]. The outer surface of the adult schistosome tegument consist of a double membrane structure, which plays an essential role in modulating host responses as well as ensuring parasite survival. As a protein localized in the tegument, it is suggested that SmKI-1 is involved in offering protection to the parasite in its mammalian host [80].

The adult worm pairs in the mesenteric veins of the small intestine of the host's blood vessels leads to hypercoagulability through changes in blood flow and endothelial function [81]. This feature and the negatively charged surface of schistosomes is most likely to trigger prompt activation of molecules involved in initiating blood coagulation. Factor XII in blood becomes activated following exposure to a negatively charged surface, such as that presented by S. mansoni, thereby triggering the intrinsic coagulation pathway. A cascade of reactions then occurs, leading to the activation of the common coagulation pathway, which ultimately results in the formation of a fibrin clot [82]. SmKI-1 has been reported to inhibit the proteolytic activities of coagulation factor $\mathrm{Xa}$, thrombokinase and plasma kallikrein, a serine protease involved in blood coagulation. This inhibition, as well as the delay in prothrombin time (PT) and activated partial thromboplastin time (APTT) for blood clot formation, suggests possible roles of SmKI-1 in both anti-inflammatory and anti-coagulation processes in the host [71]. Its potential as a vaccine candidate is discussed later in the review. 


\subsubsection{SjKI-1}

According to Virchow's triad, an alteration to normal blood flow, damaged endothelium or hypercoagulability of plasma initiates blood coagulation [83]. Adult schistosome worm pairs present in the blood vessels cause blood turbulence and disturb endothelial cell functions, thereby activating platelet formation and ultimately blood coagulation. As previously stated, the highly negatively charged nature of the schistosome surface also contributes to the activation of platelets and the intrinsic coagulation cascade [81]. In contrast to $S$. mansoni female worms, which individually deposit hundreds of eggs on a daily basis, those of $S$. japonicum deposit thousands of eggs daily into the mesenteric veins of the mammalian host [84]. Although these eggs are large enough to disturb blood flow in the smaller veins, clotting does not occur $[71,85]$. This suggests that schistosomes must have evolved mechanisms to control host hemostasis, while also inhibiting blood coagulation to ensure their long-term survival in the host blood stream.

In line with the proposed involvement of schistosomes in blood coagulation, a serine protease inhibitor belonging to the Kunitz type of serine proteases, SjKI-1 has been identified in S. japonicum species. SjKI-1 is localized in adult worms and eggs with very low expression in cercariae and the schistosomula [71]. The activity of the intrinsic and common coagulation cascades is measured by APTT and can be prolonged by deficiencies in factors XII, XI, IX, VIII or pre-kallikrein [86]. It has been reported that in the presence of SjKI-1 there is prolonged APTT, suggesting that this Kunitz protein can inhibit one or more clotting factors involved in the coagulation pathways [71]. A vast majority of blood coagulation pathways are calcium-dependent; hence, it is well known that calcium is a critical component in coagulation pathways. SjKI-1 is reported to be able to bind calcium ion successfully; this binding is postulated to contribute to the disruption of the coagulation cascade by reducing the level of free calcium ions available for the coagulation reactions [87], in this way allowing for prolonged survival of schistosomes in the blood vessels. Furthermore, SjKI-1 binds and forms a complex with both trypsin and NE, inhibiting their immune response activity with an $\mathrm{IC}_{50}$ value of $0.21 \mathrm{nM}$. SjKI-1 does not contain a signal sequence [71] and this suggests that it is not secreted via the conventional process involving cleavage of the signal peptide, but is purposely released by the parasite through an unknown excretory mechanism to facilitate its survival. This suggests the likelihood of the involvement of this protein in various biological roles promoting the survival of the schistosome parasite through its interaction with serine proteases. SjKI-1 should be evaluated further as a potential anti-coagulant as well as a potential drug target for schistosomiasis and other hematological disorders.

\subsubsection{SjB10}

It has been proposed that parasite-derived protease inhibitors, such as serpins, play essential roles in the survival of parasites through host immune evasion by interfering with hosts' immunomodulatory signals, as well as protecting the parasite from the damaging effect of exogenous host proteases [72]. In addition, serpins participate in the maintenance of cellular homeostasis through extensive regulation of endogenous proteases [88]. To date, a number of serpins have been isolated and recombinantly produced from a range of parasitic helminths including S. mansoni [89], but there are limited studies on the identification and characterization of serpins from S. japonicum and S. haematobium. These include a $64 \mathrm{kDa}$ serpin from S. japonicum SjB10, which was identified and reported to be localized in the cercariae, schistosomulae, eggs and adult male worms. This protein has an overall low sequence homology (21-65\% homology) with serpins from other parasitic helminths; however, the presence of special characteristic features in its structure, such as the serpin motif and RCL, identify this protein as a serpin [90]. Moreover, its molecular weight of $64 \mathrm{kDa}$ is consistent with other members of the serpin superfamily [51]. In addition, secondary and tertiary structure prediction analysis show that SjB10 consists of $9 \alpha$-helices and $15 \beta$-strands, correlating with other known serpins [51]. The predicted tertiary structure of $\mathrm{SjB} 10$ has exposed RCLs; this special feature of inhibitory serpins makes them easily 
accessible to target proteases [91]. These special characteristics support the notion that $\mathrm{SjB10}$ is a member of the serine protease inhibitor superfamily.

The amino acid sequence within the RCL of a serpin is a critical determinant of not only its specificity to target proteases, but also whether the serpin is inhibitory or noninhibitory [92]. This is dependent on the consensus 20/21 residue peptide ‘P17 [E]-P16 [E/K/R]-P15 [G]- P14 [T/S]-P13 [X]-P12-9 [AGS]-P8-1 [X]-P1'-4" [90]. For inhibitory serpins, P15 is usually a glycine residue, P14 is a threonine or serine and positions P12-P9 are usually occupied by short side-chain residues, such as alanine, glycine or serine. The short side chain residues allow easy and efficient insertion of the RCL into the ' $A$ ' $\beta$-sheet, a process critical to protease inhibition and subsequent conformational change in the serpin molecule. In contrast, the corresponding regions of non-inhibitory serpins do not conform to this consensus sequence [90]. SjB10 showed high conservation of primary, secondary and tertiary structure in correlation to known serpin inhibitors, suggesting that this protein most likely has an inhibitory activity. This is also supported by the high accumulation of hydrophobic amino acid residues in its hinge region, which is thought to be useful for the construction of the skeleton conformation necessary for the inhibitory activity of serpins [93]. The function of SjB10 is still speculative; however, owing to its expression in the cercarial stage, it may be released during host skin penetration to facilitate the inhibition of the host's proteases. Several proteases of the mammalian host have been tested in vitro and SjB10 is said to exhibit an inhibitory effect only on pancreatic elastase. The localization of $\mathrm{SjB10}$ in the anterior gut of the adult worm and von Lichtenberg's layer of the egg [94] proposes a possible protective role of SjB10 for the schistosome against digestion by host proteases. The $S$. japonicum egg shell has an electron opaque matrix with two layers interrupted by preformed pores [95]. Schistosome eggs must migrate through tissues of the intestine or bladder, leaving the host to re-start the life cycle, and this is facilitated by the secretion of special immune-reactive molecules from the outer envelope surrounding the differentiating miracidium $[95,96]$. During the release of secreted antigens into the surrounding host tissue through the preformed pores on the egg shell, host molecules, such as immune and digestive proteases, could consequently gain access to the egg through these pores. The localization of SjB10 within the von Lichtenberg's layer of the egg suggests a possible protective role by this protein for the parasite against a potential proteolytic attack by host digestive and immune proteases present within the intestine as the eggs migrate through this tissue [97]. SjB10 presents an interesting potential target in schistosome drug development through targeting SjB10-specific protein inhibitors. The various protease inhibitors that have critical functions in the survival and development of schistosome worms are shown in Table 2 and their functions are summarized in Figure 1.

Table 2. Schistosome protease inhibitors.

\begin{tabular}{|c|c|c|c|c|}
\hline Protease Inhibitor & Specie & Protease Inhibited & Location of Expression & References \\
\hline SmSrpQ & Schistosoma mansoni & SmCE & Cercariae & {$[74]$} \\
\hline $\mathrm{SmPi} 56$ & Schistosoma mansoni & NE & Adult worms & {$[50,71,73]$} \\
\hline ShSPI & $\begin{array}{c}\text { Schistosoma } \\
\text { haematobium }\end{array}$ & Thrombin & Surface of adult worms & {$[89,98]$} \\
\hline SjB10 & Schistosoma japonicum & $\begin{array}{l}\text { Trypsin, chymotrypsin, } \\
\text { pancreatic elastase }\end{array}$ & $\begin{array}{c}\text { Cercariae, schistosomula, eggs, } \\
\text { adult male worms }\end{array}$ & [97] \\
\hline SjB6 & Schistosoma japonicum & Trypsin & Eggs & [89] \\
\hline SmKI-1 & Schistosoma mansoni & Trypsin, chymotrypsin, NE & Adults, schistosomula, eggs & {$[67,71]$} \\
\hline SjKI-1 & Schistosoma japonicum & Trypsin, chymotrypsin, NE & Eggs, adult worms & {$[71]$} \\
\hline SmSPI & Schistosoma mansoni & Chymotrypsin, PE, NE & $\begin{array}{l}\text { Head gland of schistosomules, } \\
\text { spines of adults }\end{array}$ & [57] \\
\hline
\end{tabular}




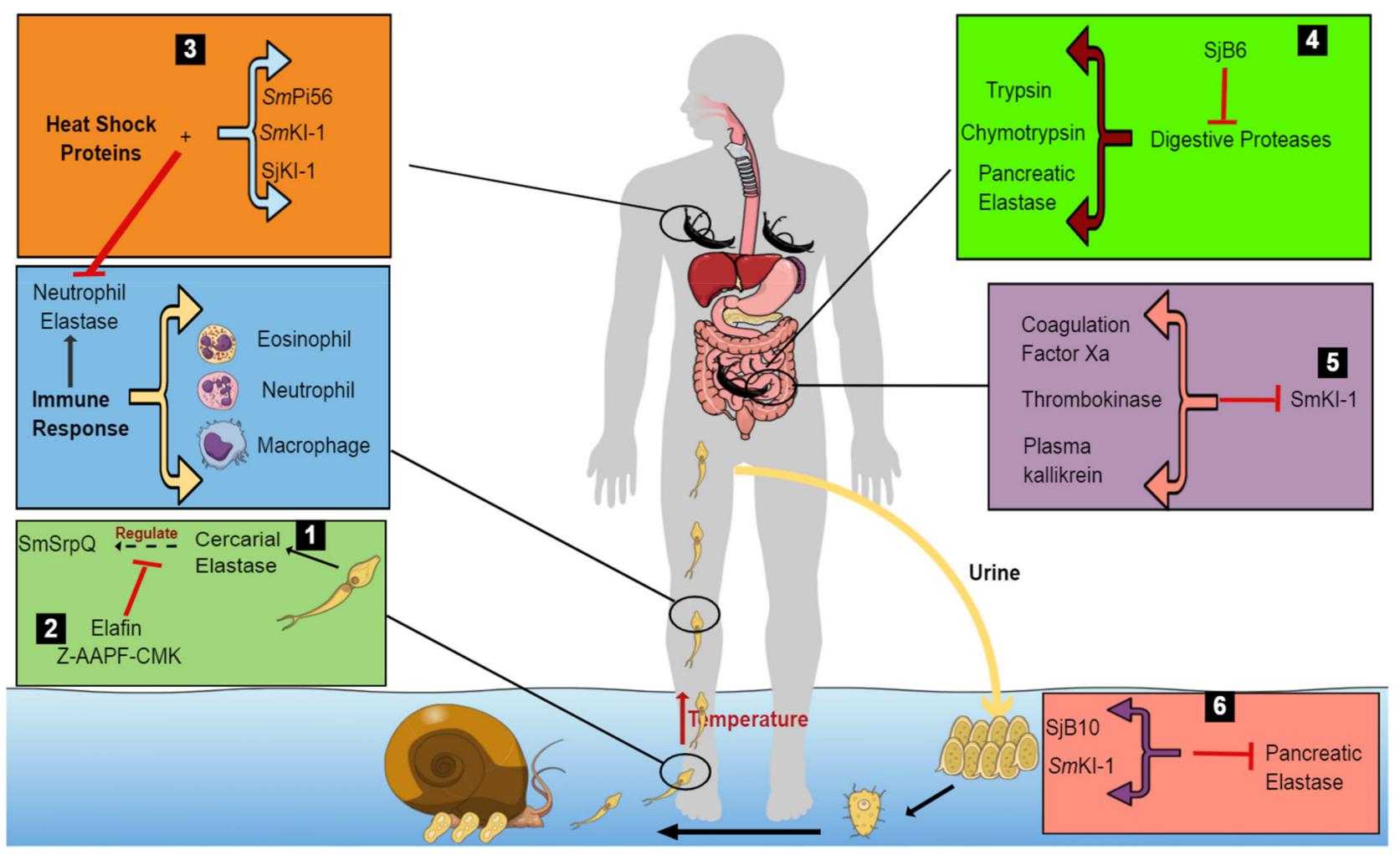

Figure 1. Model proposing the survival mechanisms of schistosomes within the host by protease inhibitors. The cercariae penetrate the human skin using cercarial elastase, which secretes a protease inhibitor, SmSrpQ. This regulates the production of cercarial elastase, in this way protecting the cercariae from its own elastase (1). The presence of CE inhibitors, Elafin and Z-AAPF-CMK, inactivates CE, blocking SmSrpQ regulation, and thus, preventing successful host penetration (2). However, in their absence, the cercariae migrate through various tissues in the host. This stimulates an immune response in the human host, leading to the release of effector cells and specific proteases such as NE to defend the human body (2). To counteract the host's immune response, schistosomules secrete various protease inhibitors (SmPi56, SmkI-1 and SjKI-1) and heat shock proteins to inhibit the effects of NE (3). In the small intestine (4), schistosomes escape digestion by digestive enzymes through the secretion of $\mathrm{SjB} 6$, which inhibits digestive proteases within the host (trypsin, chymotrypsin and pancreatic elastase). In the mesenteric veins of the host, adult worms prevent blood coagulation by secreting SmKI-1, which inhibits various blood-clotting factors, in this way interfering with blood flow to vital organs of the body (5). The worms survive and produce eggs to continue the infection cycle. These eggs are protected from the effects of pancreatic elastase by SjB10 and SmKI-1 (6).

\section{Sm29 Protein}

Currently, schistosomiasis control strategies are mainly focused on the treatment of infected individuals by chemotherapy with the safe and effective drug PZQ [99]. Despite decades of chemotherapy, the number of infected people is still almost the same, especially in resource-poor settings with little or no access to proper health care facilities [100]. Constant re-infection of individuals, together with poor sanitary conditions in tropical countries, necessitates venturing into control strategies other than dependence on a single drug treatment plan [100]. Vaccination could be an interesting approach to supplement the available drug in an attempt to reduce infection rates. In schistosomiasis a vaccine that results in even a partial reduction in worm burdens could potentially reduce pathology to a considerable level and limit parasite transmission [101]. After decades of repetitive treatment with the preferred drug for schistosomiasis, many world health agencies support the notion that immunization with an anti-schistosomal vaccine presents a better long-term strategy to control schistosomiasis [102]. Hence, there has been an increase in studies looking into testing different antigens of the parasite and various vaccination strategies [101]. Proteins that are secreted or fixed on the surface of schistosomes are easily 
exposed to host tissues, and thus, have a higher chance of presenting as potential candidate molecules for the development of new vaccines. In mice, it has been reported that isolated tegumental membrane antigens can stimulate protective immunity [103]. Studying proteins anchored in the tegument of schistosome worms is, therefore, essential to improve functional understanding of the tegument at a more advanced level to identify molecules that may act as targets for protective immune responses or may be useful in diagnosing schistosomiasis [104].

Schistosoma mansoni 29 kilodalton protein $(S m 29)$ is a membrane-bound protein that is highly expressed on the tegument of $S$. mansoni worms; its expression is not seen in the internal tissues of the parasite. The amino acid sequence of $S m 29$ possesses a signal peptide and a transmembrane region as well as cysteine-rich domains that form disulfide bridges, which confers stability to this glycoprotein [105]. This transmembrane protein is present in the schistosomula and adult stages of the parasite, and has been implicated in several immune response interactions, thus making it an important vaccine target.

Previous analyses of immune responses in experimental and human schistosomiasis have shown that antibodies are capable of killing schistosomula in the presence of phagocytic cells, such as macrophages, platelets and eosinophils, and these have been reported to be able to confer resistance to infection [106]. Thus, studying the different functional properties of antibody isotypes is essential to understand the predictive information regarding disease progression and the efficacy of vaccination. Extracellular pathogens enter the human body across the epithelial barriers of the mucosa lining the respiratory, digestive and urogenital tracts, or through damaged skin, and can then establish infections in the tissues. Antibodies must, then, be widely distributed to neutralize or completely eliminate the pathogen. A study was conducted to investigate the antibody isotype profile specific to Sm29 antigen in the sera of resistant individuals in comparison to ones who are susceptible to infection and re-infection in a schistosomiasis-endemic area in Brazil. Two Sm29-specific antibodies, IgG1 and IgG3, were used in conducting this investigation and it was reported that isotypes related to opsonization, cell-dependent cytotoxicity and activation of the classical complement pathway were present in significant levels in individuals resistant to infection and re-infection [105]. This, therefore, presents the Sm29 antigen as a target to antibody-dependent cell cytotoxicity (ADCC) effector mechanisms mediated by IgG1 and IgG3. Furthermore, these antibodies, in addition to their role in opsonization, celldependent cytotoxicity, and the ability to activate the classical complement pathway, are actively involved in protective immunity of the host [107]. IgG2 and IgG4 are often released in response to antigens activated during $S$. mansoni infection to block the effect of protective antibodies mediating ADCC reactions against the schistosomula by reacting with parasite surface glycoproteins, preventing the functional effector mechanisms involved in parasite killing. In the presence of Sm29, significantly low levels of these antibodies are observed, implying that this antigen does not stimulate the production of these antibodies [108]. The IgG4 response has also been linked to increased susceptibility to infection [109]. It can, therefore, be concluded that the absence of IgG2 and IgG4 in the presence of this transmembrane antigen might be an important humoral attribute that contributes to the protection of the mammalian host against schistosomiasis and presents $S m 29$ as a potential vaccine candidate.

It has also been reported that mice immunized with $5 m 29$ showed high levels of protection with significant reduction in worm burden, liver granulomas and intestinal eggs. This protection is associated with a typical Th1 immune response. In addition, schistosomes that were recovered from Sm29-vaccinated mice showed no upregulation of heat shock or chaperone genes that are usually employed by these parasites to escape unfavorable developmental stages [105]. Sm 29 is reported to form part of the $16 \%$ of highly expressed proteins in S. mansoni, suggesting that it plays an important role in the biology of the worm [110]. It has been reported that one of the proteins found to interact with $S m 29$ is an inhibitor of the membrane attack complex, CD59, which is mainly used by many viruses as an immune evasion tactic [5]. Experimental exploration of the interaction between $S m 29$ 
and CD59 could provide insights on how S. mansoni parasites inhibit the membrane attack complex and give rise to strategies that could prevent this inhibition.

\section{Sm14 Protein}

Schistosomes are known to lack the oxygen-dependent pathways required for the synthesis of sterols and fatty acids. For this reason, these parasites are solely dependent on their host for these and other essential lipid supplies [111]. Schistosomes are only capable of synthesizing phospholipids and triacylglycerols from precursors obtained from the host, such as the low-density lipoproteins of the blood in which the parasites reside [112]. These parasites have a strong requirement for lipids for the synthesis and maintenance of their complex membrane systems. Fatty acids act as precursors for lipid and phospholipid synthesis and it is, therefore, safe to imply that they are a critical component in the life cycle of the parasite, playing a role in membrane formation, functioning as lipid anchors for proteins and sexual maturation and regulating egg production $[38,113]$. Fatty acidbinding proteins (FABPs) are predominantly important for the uptake, transport and compartmentalization of host-derived fatty acids and are considered a potential target for vaccine development. The $14 \mathrm{kDa}$ S. mansoni (Sm14) antigen was the first FABP homologue identified in helminths [38,114]. Sm14 elicits a T helper cell type 1-(Th1) mediated immune response that is associated with resistance to schistosomal infection in individuals from endemic regions in Brazil [38]. This correlates to an earlier study that proposed that this protein stimulates a protective response against schistosomiasis [115]. Sm14 has been postulated to interact with Sm29 and the fusion protein is termed FSm14/29 [116]. Taking into account the critical functions of both antigens in schistosomal infection, their combined effect has been tested and will be explained later in this review.

\section{Heat Shock Proteins}

For schistosomes to survive, their proteome needs to be able to meet the demands of the hostile conditions associated with the alternating hosts and environments characterized by variable physiological conditions such as changes in $\mathrm{pH}$, temperature and nutrient supply [117]. In contrast to free-living parasites, schistosomes are prone to undergo extensive molecular evolution during their developmental cycles, promoting the chances of producing mutated proteins and making their proteome aberrant. It is for this reason that schistosomes require a robust protein folding system to increase their survival chances. As such, schistosomes use the heat shock protein (Hsp) machinery to escape the various insults associated with their life cycle [118]. Hsps form part of the cell's response to stress; they are conserved and ubiquitous molecules that facilitate folding of other proteins (substrates/clients) during cellular stress [119]. Various heat shock response-related genes, including Hsp40 [120], Hsp90 [121], Hsp70 [122,123] and Hsp60 [124], have been identified in schistosomes. The most extensively studied group of stress proteins in schistosomes belongs to the Hsp70 family [118]. The remarkable conservation of its primary structure and its expression in a number of organisms make it an interesting target for diagnosis and treatment in various diseases. The therapeutic potential of Hsp70 in schistosomiasis has been explored in the literature $[35,122,125]$. Although Hsp70 is regarded as a potential drug target, its expression is only pronounced in the cercaria-shistosomula stage of the parasite. Studies reveal that treatment of cercariae with an Hsp70 inhibitor results in a change in the swimming behavior of the worm, reducing the chances of successful penetration of the host [126]. In contrast, Hsp60 is reported to be constitutively expressed throughout the entire life cycle of the worm, where it plays a major role in import and protein folding in the transition from cercariae to schistosomula [127] and is proposed to play a role in the survival of the schistosome under hostile conditions, thus making Hsp60 an interesting target for the treatment of schistosomiasis. 


\subsection{S. mansoni Hsp60}

The $60 \mathrm{kDa}$ Hsp is a specialized but ubiquitous group of molecular chaperones, generally known to form large oligomeric rings and function in folding of nascent polypeptides transported to the mitochondria with the assistance of the co-chaperonin, Hsp10, in an adenosine triphosphate (ATP)-dependent manner. The mechanism by which this protein allows for the survival of the worm has not yet been elucidated. We, therefore, propose, based on the mechanism of action of the human Hsp60, that after the exposure of the worm to the defense mechanism of the snail host, changes in temperature or the immune response of the human host upon penetration induces increased expression of S. mansoni Hsp60. Temperature variations have been suggested to influence the complex interactions that occur between schistosomes and their intermediate snail host [128]. A number of studies revealed that schistosomes have reduced tolerance to low temperatures, while their intermediate snail hosts show better tolerance to lower temperatures $[129,130]$. It has been reported that the rate at which miracidia mature to cercariae within the snail is relatively slow during cold weather conditions and cercarial shedding is subsequently reduced. Additionally, low S. mansoni infection rates have been reported for snails kept at lower temperatures $\left(23\right.$ to $25^{\circ} \mathrm{C}$ ) in comparison to those kept at higher temperatures of 26 to $28^{\circ} \mathrm{C}$ [128]. A rise in temperature from $26^{\circ} \mathrm{C}$ to $32^{\circ} \mathrm{C}$ has been reported to result in an increased shedding of $\mathrm{S}$. mansoni cercariae; although these temperature conditions favor transmission of infection, they are detrimental to the snail host [131]. Mangal et al. [130] showed that constant high temperatures $\left(>35^{\circ} \mathrm{C}\right)$ result in low cercarial production, high snail mortality and eventually cause changes in the dynamics of the disease from stable endemic infection to unstable infection. Similarly, Adekiya and colleagues [128] also reported that temperatures above the optimal $\left(26\right.$ to $\left.32{ }^{\circ} \mathrm{C}\right)$ result in a decrease in the infection rate of the parasite due to the low abundance in snail production, thus limiting the growth and development of the parasite.

As previously mentioned, these hostile conditions lead to abnormal changes in the proteome of the worm, such as unfolding of proteins. In the absence of defense mechanisms of the worm, the loss of the three-dimensional structure of proteins within the worm, accumulation and aggregation of unfolded proteins would result in reduced cell viability and tissue dysfunction. This will ultimately reduce the ability of the worm to perform its function and eventually lead to its death. In the presence of S. mansoni Hsp60, unfolded polypeptides exposing hydrophobic amino acid residues bind to the apical domain of S. mansoni Hsp60 that is not yet occupied by its co-chaperonin S. mansoni Hsp10 [132]. Subsequently, Hsp10 and ATP bind to the S. mansoni Hsp60 polypeptide complex, forming a cis ring complex. Binding of S. mansoni Hsp10 results in the burial of the hydrophobic polypeptide recognition regions of the apical domain of S. mansoni Hsp60, allowing for the subsequent release of the bound non-native substrate into the central cavity [133]. The non-native substrate is encapsulated in a comparatively polar environment, which supports folding and the formation of the native polypeptide state [134]. Folding of the non-native substrate is controlled by ATP, in the sense that the substrate is allocated about 15 to $30 \mathrm{~s}$ to fold prior to ATP hydrolysis [135]. Hydrolysis of ATP triggers the dissociation of S. mansoni Hsp10 from S. mansoni Hsp60, opening the folding cage and allowing for the subsequent release of the native form of the polypeptide (Figure 2). Generally, substrate proteins undergo repeated rounds of folding before the attainment of the native state; hence, substrates that were not properly folded are rapidly captured and undergo a second round of assisted folding. In this way, the parasite is able to escape the hostile conditions associated with its life cycle and to develop into adult worms that produce eggs that re-start the infection cycle. Owing to the important role played by S. mansoni Hsp60, the development of specific inhibitors that target this protein and can modulate its function in schistosomes can be an interesting approach in the design and development of antischistosomal drugs. 


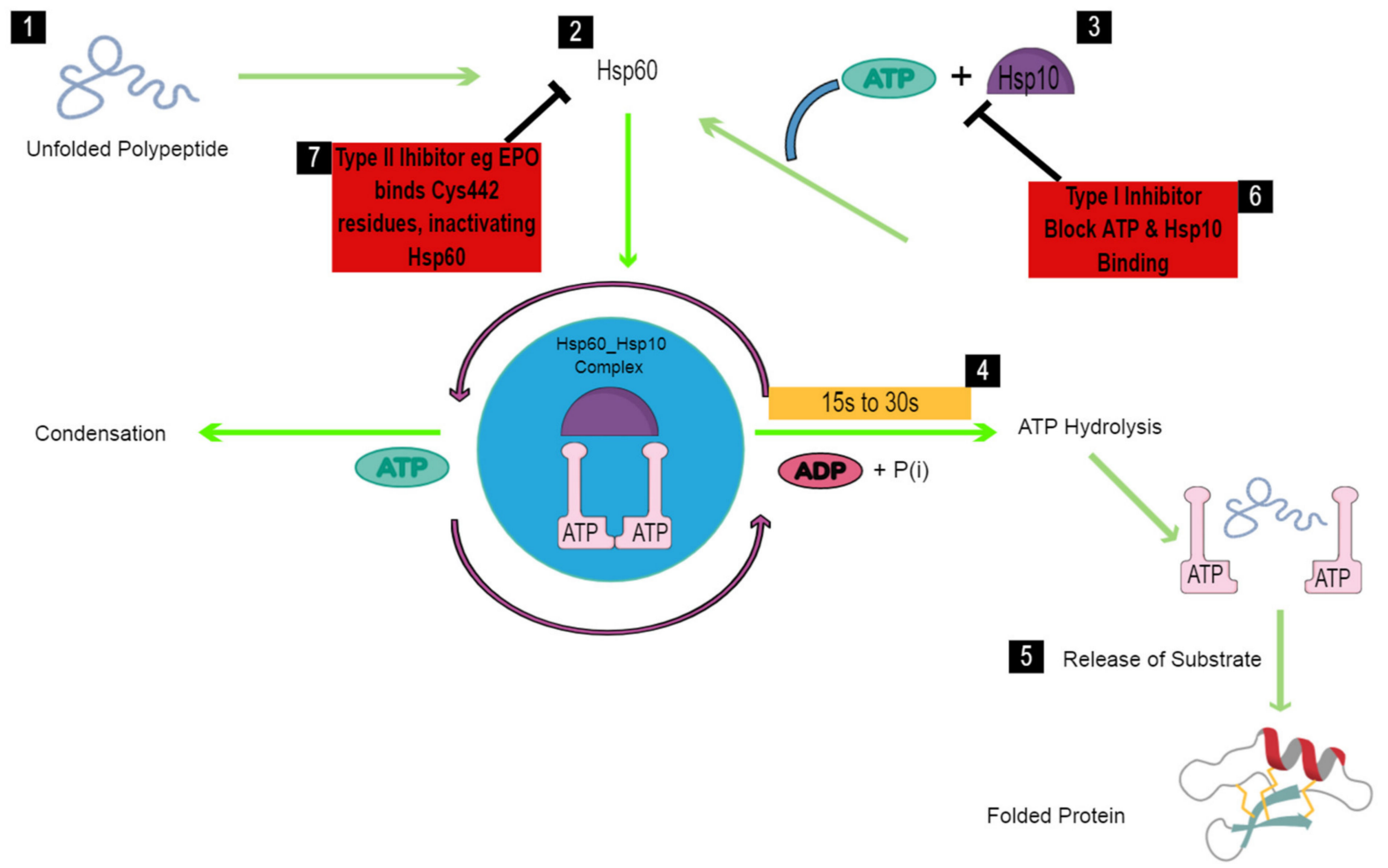

Figure 2. Schematic diagram of the folding mechanism of the schistosomal Hsp60-Hsp10 complex. In the human host, schistosomes are exposed to extreme temperatures that result in unfolding of their proteins (1). Increased temperature conditions within the worm stimulate the expression of Hsp60, which binds the unfolded polypeptide (2). Hsp10 and ATP immediately bind to Hsp60, forming an Hsp60-Hsp10 complex that facilitates folding in an ATP-dependent manner (3). Protein folding is, therefore, expected to occur within 15-30 s prior to ATP hydrolysis (4), which leads to the release of the bound polypeptide (5), and thus, the worm regains functionality and survives. To block the chaperoning activity of Hsp60 in schistosomes, a type I Hsp60 inhibitor such as Mizoribine binds to Hsp60, blocking ATP and Hsp10 binding, and thus, preventing protein folding (6). A type II Hsp60 inhibitor, Epolactaene, binds the Cys442 residue, thus inactivating Hsp60 prior to binding of the unfolded polypeptide (7).

\subsection{Hsp60 Inhibitors}

Although a number of inhibitors have been developed for various Hsps, very few have been developed for Hsp60. Known Hsp60 inhibitors are from either natural or synthetic compounds and are grouped into two types [43,136]. Type I inhibitors block ATP binding and hydrolysis, subsequently blocking the Hsp60/10 refolding machinery because the ATP-dependent conformational changes are affected. Type II inhibitors are compounds that bind to the cysteine residues of Hsp60; however, details of their binding sites and mechanism of action are not yet understood. Natural compounds known to inhibit Hsp60 are mizoribine, epolactaene and myrtucommulone, while $o$-carboranylphenoxyacetanilide 8 and gold (III) porphyrin are Hsp60 inhibitors from synthetic sources [137]. To date, there have been no reports on the structure of schistosomal Hsp60; hence, inhibitors targeting the schistosomal homolog have not yet been identified.

\section{Current Status of Schistosomiasis Treatment}

The drive to control as well as eliminate schistosomiasis continues, with various strategies being put in place. However, despite all the efforts made, there is still a gradual rise in the number of schistosomal infections. To date, no new drug has been approved as an alternative to PZQ [138]. The WHO recommends the use of PZQ for the treatment of schistosomiasis in view of its effectiveness against all three Schistosoma species known to infect humans [3]. However, the drawbacks associated with its use necessitate improved 
and affordable treatment methods, including targeting protein interactions observed during the course of schistosomal infection.

Although PZQ remains the only accepted and available treatment for schistosomiasis, other drugs have been introduced but have faced limited use. Combination treatment of PZQ with one of the drugs that have been taken off the market, artemether, has been reported to have higher efficacy levels. Artemisinins are derived from extracts of sweet wormwood (Artemisia annua), a plant endemic to China, and are well established for their antimalarial activity. Their efficacy also extends to related parasitic infections, as they have been found to possess anti-schistosomal properties [139]. In support of this, a derivative of artemisinins, artemether, has effectively controlled S. mansoni and S. japonicum infections in areas of high endemicity such as in China [11]. In contrast to PZQ, derivatives of artemisinins, such as artemether, are more effective against immature schistosomes and show reduced efficacy against the invasive adult stages [140]. Although artemether alone is associated with lower cure rates than $\mathrm{PZQ}$, results from clinical trials show that a combination of artemether and PZQ is more effective than PZQ alone [14]. Therefore, joint treatment would target all the developmental stages of the parasite in its definitive host and consequently prevent re-infection. A limitation to the use of artemisinin derivatives in the treatment of schistosomiasis is the risk of the development of resistant plasmodia, especially in sub-Saharan Africa, where schistosomes and Plasmodium species co-exist.

Previous studies have put forward a notion that in conjunction to improvements that can be made in terms of adherence to treatment and ensuring wide access to available treatment, the development of potential vaccine candidates offers the best option to increase the possibility of achieving WHO goals of eliminating this disease [141]. Although the current drug has been effective to some extent, there is general agreement among experts that sustainable reduction in the transmission and disease burden of schistosomiasis can only be achieved through vaccination. An effective anti-schistosome vaccine would greatly contribute to reduced schistosomiasis-associated morbidity through protective immune responses, leading to reduced worm burdens and decreased egg production [142,143]. There is currently no schistosomiasis vaccine, although a number of candidates are in various stages of clinical trials (Table 3).

\subsection{Tetraspanin Proteins}

Tetraspanins (TSP) are four transmembrane domain proteins that are found exposed on the surfaces of all multicellular eukaryotes [144]. These proteins are often localized at the plasma membrane and they interact with one another, as well as with immunoglobulin superfamily proteins, proteases and receptors. Through these interactions, they mediate various functions, including the regulation of cell signaling, cell proliferation, adhesion, spreading, migration, cell-cell fusion and pathogen entry of a number of diseases [145]. In schistosomes, TSPs are abundant in both the larval and adult stages of the parasite and while the exact functions of schistosome tetraspanins are unknown, their mammalian homologs are associated with partner proteins in the basolateral domains of the plasma membrane and function in cell-cell interactions and maintenance of cell membrane integrity. It is, therefore, believed that schistosome tetraspanins might perform a similar role in the tegument [146]. The failure to develop an antischistosomicide with high efficacy can be attributed partly to the complex immune-evasive strategies employed by the parasite to avoid elimination from its intravascular environment. Schistosomes have a unique outer syncytial surface, the tegument, which constitutes the host-parasite interface, and thus, represents an interesting tissue to target for the development of new control strategies. This can be achieved by identifying proteins that contain membrane-targeting signals that are expressed in the tegument. 
Table 3. Anti-schistosomal vaccine candidates.

\begin{tabular}{|c|c|c|c|c|c|}
\hline Antigen & Location & Target Species & Function & $\begin{array}{c}\text { Vaccine } \\
\text { Development Stage }\end{array}$ & References \\
\hline Sm-TSP-2 & Tegument & S. mansoni & $\begin{array}{l}\text { Maintains tegument } \\
\text { creation and } \\
\text { maturation in the } \\
\text { adult worm }\end{array}$ & Phase I & [146] \\
\hline Sj97 & $\begin{array}{c}\text { Tegument of } \\
\text { schistosomula and } \\
\text { penetration glands of } \\
\text { the cercariae }\end{array}$ & S. japonicum & $\begin{array}{l}\text { Associated with } \\
\text { resistance to infection } \\
\text { and re-infection }\end{array}$ & Pre-clinical & [2] \\
\hline $\operatorname{Sm} 97$ & $\begin{array}{l}\text { Tegument and } \\
\text { cercariae }\end{array}$ & S. mansoni & $\begin{array}{l}\text { Offers protective } \\
\text { immunity to the host }\end{array}$ & Pre-clinical & [147] \\
\hline Sm-p80 & $\begin{array}{l}\text { All developmental } \\
\text { stages of S. mansoni }\end{array}$ & S. mansoni & Immune evasion & Pre-clinical & [148] \\
\hline $\operatorname{Sm} 29$ & Tegument & S. mansoni & $\begin{array}{l}\text { Protection against } \\
\text { re-infection }\end{array}$ & Pre-clinical & [116] \\
\hline SmKI-1 & $\begin{array}{c}\text { Tegument and } \\
\text { sub-shell region of } \\
\text { eggs }\end{array}$ & S. mansoni & $\begin{array}{l}\text { Inhibits host proteases; } \\
\text { permits parasite } \\
\text { survival }\end{array}$ & Pre-clinical & [71] \\
\hline
\end{tabular}

The major TSP proteins in S. mansoni are Sm-TSP-1 and Sm-TSP-2. The full-length Sm-TSP-2 is a protein proposed to play a role in both tegument creation and maturation in the adult worm $[2,149]$. To determine the potential of these proteins as vaccine candidates, a study was conducted involving the vaccination of mice with recombinant Sm-TSP (rSmTSP) proteins, which resulted in reductions of $57 \%, 65 \%$ and $64 \%$ in rSm-TSP- 2 and $34 \%$, $69 \%$ and $52 \%$ in rSm-TSP-1 for mean adult worm burdens, fecal egg counts and liver egg burdens, respectively. Fecal egg counts were drastically reduced by $65 \%$ and $69 \%$, respectively, in both test groups. In particular, $\mathrm{rSm}$-TSP-2 provided protection to mice over the $40 \%$ benchmark set by the WHO for the progression of schistosome vaccine antigens into clinical trials. Additionally, Sm-TSP-2 is strongly recognized by IgG1 and IgG3 antibodies from individuals that are naturally resistant to schistosomiasis, although exposed. This, in addition to the vaccine efficacy in mice, highlights the potential of SmTSP-2 as a safe and effective vaccine for human schistosomiasis [146]. It is postulated that tetraspanins in the tegument of schistosomula and adult worms may be receptors for host ligands, so vaccination with Sm-TSP-2 could induce antibodies that interfere with the interactions between these tetraspanins and their host ligands, thereby blocking crucial immune-evasive strategies by the parasite, thus rendering the schistosome surface vulnerable to an effective immune response [146,150].

The safety and immunogenicity of a candidate $S m$-TSP vaccine has been assessed in a Phase I, double-blind, dose-escalation trial in which 72 healthy adults from a nonendemic area, aged 18-50 years, were randomized to receive three doses of recombinant $\mathrm{Sm}$ Tetraspanin-2 vaccine formulated on aluminum hydroxide adjuvant (Sm-TSP-2/Al), with or without the adjuvant, as well as a glucopyranosyl lipid A aqueous formulation (GLA-AF), at intervals of approximately eight weeks between doses. Assessing clinical and serologic responses after the treatment, it was observed that anti-Sm-TSP-2 IgG responses were noticeably lower among recipients of Sm-TSP-2/Al without GLA-AF, while the recipients of Sm-TSP-2/Al with GLA-AF showed significant increases in IgG to Sm-TSP-2 [139]. It can, then, be concluded from this study that Sm-TSP-2/Al with or without GLA-AF is safe and well tolerated, although minor side effects such as headaches and pain at the injection site have been reported. In the United States and Brazil, Phase I clinical trials for the Sm-TSP-2/Alhydrogel ${ }^{\circledR}$ schistosomiasis vaccine continue to determine the toxicity, safety and immunogenicity of this vaccine in healthy adults [148]. 


\subsection{Paramyosin}

Paramyosin is a myofibrillar $97 \mathrm{kDa}$ protein anchored in the muscle layers and the tegument of schistosomes that has for many years been regarded as a potential vaccine candidate against S. japonicum (Sj97) and S. mansoni infection associated with resistance to infection and re-infection [2]. An earlier study showed that mice vaccinated with purified paramyosin free of an adjuvant resulted in $62-86 \%$ resistance against $S$. japonicum infection [151]. In addition to preventing infection, a longitudinal treatment re-infection study conducted in the Philippines, with Sj97 showing a longer time for humans to become re-infected and even lower re-infection intensity after treatment with PZQ [152,153]. Furthermore, it was reported that individuals who produce IgE but not IgG4 in response to $\mathrm{rSj} 97$ have a $77 \%$ lower re-infection chance after 12 months or more of treatment with PZQ [152]. Sj97 is now undergoing early preclinical testing to assess its efficacy and safety $[142,149,152]$. In the case of S. mansoni, a study to determine the efficacy of Sm97 antigen in immunized mice, found that $\mathrm{S} m 97$ induced $44.1 \%, 59.1 \%$ and $61 \%$ reduction in worm burden, intestinal egg loads and granuloma size, respectively, compared to the infected control group. Moreover, increased protective immunity was observed in mice and this was associated with high levels of specific anti-Sm97 IgG1 and IgG2 antibodies [147].

\subsection{Calpain}

Calpain is a calcium-activated neutral cysteine protease localized in the tegument of all developmental stages and inner tegument membrane of adult schistosome worms. It is a central antigenic protein in surface membrane biogenesis and renewal, which is a common mechanism frequently used by schistosomes to escape the harmful host immune response [148]. The inactivation of calpain has an inhibitory effect on the C3b component of complement and 5-hydroxytryptamine signaling pathways, bringing about the acceleration of surface membrane synthesis. The large subunit of calpain is called Sm-p80 and is putatively expressed in all developmental stages of S. mansoni [143,154], making this antigen an excellent target for a schistosome vaccine because of its consistent immunogenicity, protective and anti-fecundity potentials, as well as its proposed important role in the immune evasion process [155]. Prime-boost vaccination (priming with DNA and boosting with recombinant protein) with Sm-p80, in combination with a resiquimod adjuvant, results in a $49 \%$ worm burden reduction, whereas $50 \%$ protection can be observed when using the recombinant protein (Sm-p80/GLA-SE) as primary and boost vaccine (immunized and then boosted by recombinant protein) in mice [156]. Following the same approach, but with a different adjuvant, oligodeoxynucleotide (ODN) 10104, a 70\% worm burden reduction was reported with a 75\% egg reduction, suggesting that ODN 10104 increases the efficacy of Sm-p80. The vaccine also elicits strong immune responses that include IgM, IgA and IgG isotypes [155]. This antigen has been tested in baboons (Papio anubis), where a considerable worm burden reduction of $58 \%$ was observed with the Sm-p80-based vaccine adjuvanted with resiquimod and CpG ODN [157]. Moreover, the vaccine provided levels of protection against $S$. mansoni infection in baboons comparable to those achieved by the irradiated cercarial vaccine. Antibodies and IFN- $\gamma$ were shown to play a crucial role in the protective immunity observed in this non-human primate model [158]. In addition, it has been shown that $\mathrm{Sm}-\mathrm{p} 80$ has a therapeutic effect in vaccinated baboons through a reduction in the numbers of established worms, reduced retention of eggs in tissues and decreased number of eggs excreted in feces [155].

Interestingly, Sm-p80 has been shown to provide cross-species protection against $S$. haematobium in hamsters and baboons. A $64 \%$ reduction in tissue egg load and a $48 \%$ reduction in worm burden were observed in hamsters vaccinated with recombinant Smp80/GLA-SE. Similarly, in baboons, it resulted in a $64 \%$ egg load decrement in the urinary bladder and a 53\% reduction in urine egg output [2]. A balanced pro-inflammatory (TH17 and TH1) and TH2 type response consequently occurred after vaccination, indicating that the Sm-p80 vaccine is effective against both intestinal and urinary schistosomiasis and will, thus, be significantly advantageous in reducing the overall burden of schistosomiasis [154]. 
The recombinant Sm-p80/GLA-SE vaccine, "SchistoShield," is expected to move forward to Phase I and II human clinical trials $[97,149,159]$.

\subsection{S. mansoni 29 Kilodalton Protein}

Specific antibodies against Sm29, IgG1 and IgG3 are detected in sera of patients living in endemic areas of Brazil and significantly higher levels of these antibodies were found in individuals who are resistant to re-infection [105]. Mice immunization with $\mathrm{rSm} 29$ has been shown to result in a significant reduction in adult worm burdens, liver granuloma counts and intestinal eggs, as previously stated. In addition, three doses of $\mathrm{rSm} 29$ are enough to elicit significant host protection levels, ranging from $26 \%$ to $48 \%$, to induce significant production of IL-2, IFN- $\gamma$, IL-17 and IL-4, as well as specific antibodies such as IgG, IgG1, $\operatorname{IgG3}$ and IgE, and an increase in the percentage of CD4+ central and effector memory cells. It has been proposed that $\mathrm{rSm} 29$ is capable of inducing protection in previously infected animals, reinforcing its potential as a vaccine candidate [160]. Immunizing mice with Sm29 vaccine preparation containing alum as an adjuvant (Sm29Alum) has been shown to render protection against re-infection at levels between $29 \%$ and $37 \%$. On the contrary, immunization with the Mono-phosphoryl Lipid A adjuvant (Sm29MPLA) does not provide any protection against reinfection. In particular, immunizing mice with Sm29Alum formulation resulted in higher production of IgG, IgG1 and IgE following all immunization doses. Therefore, it can be concluded that Sm29Alum effectively protects against $S$. mansoni reinfection in mice [161].

Proteins usually form complexes to elicit a specific function. Examples of these include Sm29 and Sm14, which form a fusion protein designated FSm14/29. The efficacy of the fusion protein has been tested in mice where Polyinosinic-poly cytidylic acid [poly (I:C)] adjuvanted and unadjuvanted FSm14/29 vaccinated mice showed a significant reduction in adult worm burdens of $48.4 \%$ and $44.7 \%$, respectively. In addition, significant reductions of $82.8 \%$ and $73.5 \%$, respectively, were observed in liver egg burden. Likewise, the intestinal egg count reduction reached $72.8 \%$ and $76.6 \%$ for the adjuvanted and unadjuvanted FSm14/29 antigen, respectively. Finally, adult worms recovered from immunized mice displayed deleterious structural changes. Another study showed that fusing Sm29 with Sm-TSP-2 results in increased worm burden reductions from $22 \%$ to $35 \%$, a higher titer of IgG1 and IgG2 antibodies, as well as improved levels of IFN $\gamma$ and TNF- $\alpha$ than when Sm29 is used alone in challenged mice $[149,162]$. It is clear that the adjuvant greatly improves host protection and combines the concept of using multi-antigen fusion proteins as vaccine candidates against $S$. mansoni [116].

\section{5. $\operatorname{Sm} 14$}

Sm14 has long been considered a potential vaccine candidate because of its critical biological function in facilitating absorbance, transport and compartmentalization of fatty acids from the host [163]. Recombinant $\mathrm{Sm} 14$ (rSm14) was tested in mice for host protection and it was shown that it provides up to $67 \%$ protection in terms of a reduced S. mansoni worm burden in mice without the use of an adjuvant. Reassuringly, no autoimmune response was observed even though its structure is identical to the basic form of mammalian host homologues [115]. Moreover, it has been shown to be cross-species protective against both S. mansoni and Fasciola hepatica infection. The development of a dual vaccine effective against both fluke infections will be a great milestone in terms of human and animal health Recombinant Sm14 with glucopyranosyl lipid adjuvant stable emulsion (GLA-SE) adjuvant has entered and successfully completed Phase I clinical trials in healthy adult volunteers in Brazil, authorizing its status as safe and immunogenic [164].

The Phase I clinical trial of adjuvanted $\mathrm{rSm} 14$ was conducted on 20 male volunteers from a schistosomiasis non-endemic area in Brazil. Thirty days after the first vaccination, significant increases in Sm14-specific total IgG, IgG1 and IgG3 were observed, and in IgG2 and IgG4 after 60 days. Additionally, $88 \%$ of vaccinated subjects were shown to produce high titers of Sm14-specific IgG antibody 90 days after the first vaccination injection. A 
complex mixture of Th1 and Th2 cytokines are released from peripheral blood mononuclear cells after rSm-14 stimulation. The Th1 response is characterized by IFN and TNF; these cytokines are responsible for controlling the effects of parasite eggs on the liver, a situation that is rapidly followed by a strong egg-induced Th2 response (IL-5, IL-10), which prevents severe consequences and protects the liver by downregulating the inflammatory mediators. The rSm14/GLA-SE vaccine presents itself as a strongly immunogenic and safe vaccine [164]. Further immunogenicity and safety Phase II trials of rSm14/GLA-SE are intended for schistosomiasis-endemic areas in Brazil and Africa [165].

\subsection{Schistosoma mansoni Kunitz Type Protease Inhibitor}

The Kunitz inhibitor is a $16 \mathrm{kDa}$ Kunitz-type protease inhibitor (KI-1) actively present in the excretory-secretory products, tegument of adult worms and the sub-shell region of eggs. Schistosoma mansoni KI-1 inhibits numerous proteases, which possess anti-inflammatory and anti-coagulant properties, in this way supporting parasite survival in an extremely hostile environment and perhaps playing a critical role in host immune modulation. Secretion of SmKI-1 by schistosome eggs was previously explained as important for their migration through the intestinal wall and into the gut lumen for excretion in human stool to the external environment. To confirm the effect of this inhibitor, rSmKI-1 vaccine trials were performed in mice and a reduction of $23-33 \%$ in adult worms, $28-31 \%$ in intestinal eggs, $33-39 \%$ in fecal eggs and $20-43 \%$ in liver eggs was observed. Moreover, rSmKI-1 increased the production of IFN- $\gamma$, IL-10 and IL- 6 to a considerable level in vaccinated mice, maintaining a Th1/Th2 type balanced response. Recombinant SmKI-1 resulted in partial protection against $S$. mansoni in the murine model of infection and could be established as part of a combination vaccine with other vaccine candidates to provide a more solid level of protection $[71,166]$.

\subsection{Schistosoma mansoni Asparaginyl Endopeptidase (SmAE/Sm32)}

Sm32 is a cysteine protease of the legumain family [167] that is released as an excretorysecretory material, where it is actively involved in the hydrolysis of pro-proteins that are involved in the degradation of hemoglobin expressed in the gastro-dermal cells of the schistosome gut and head glands of the cercariae [148]. Moreover, Sm32 has been found to be the principal source of amino acids for the parasite. This antigen induces an antibody-mediated inhibition of its catalytic activity, in this way preventing the processing of cathepsins such as B and L, which are actively involved in hemoglobin digestion, making it an interesting potential vaccine target for schistosomiasis. The inhibition of the above-mentioned activities has been shown to result in intense reduction in the egg burden of adult worms [168]. Additionally, the immunolocation of Sm32 in the head glands of cercariae [169] suggests a possible function of this protease in host tissue invasion. Therefore, Sm32 could be considered an interesting target, as it affects the nutrition of adult worms, thereby reducing worm burden, viability and fecundity, while simultaneously interfering with host penetration by cercariae [170].

\section{Future Prospects of Protein Vaccine Candidates against Schistosoma Infection}

Vaccine development is a long process that can take decades. To date, three schistosome protein vaccine candidates that have been produced by good manufacturing procedures have entered safety and immunogenicity human clinical trials. These are Sm14 [171], Sm-TSP-2 [148] and Sm-p80 [159]. Phase I clinical trials of rSm14/GLA-SE products indicated that they were safe and strongly immunogenic against schistosomiasis in healthy individuals. The next phase of testing is expected to take place in schistosomiasis-endemic areas of Brazil and Africa [164,171]. The Sabin Vaccine Institute product development partnership is focusing on the development of the Sm-TSP-2/Alhydroge ${ }^{\circledR}$ schistosomiasis vaccine. This vaccine entered Phase I in 2017 to determine immunogenicity, reactogenicity and safety in healthy, non-infected adults in the United States and Brazil [148]. Moreover, the recombinant Sm-p80/GLA-SE vaccine, "SchistoShield ${ }^{\circledR}$," has entered Phase I and II 
clinical trials [149]. Other antigen candidates that are in pre-clinical trials at various stages include Sm97, Sm29 and SmKI-1 for S. mansoni infection [4].

Gene sequencing of schistosome species and modern proteomics methods have significantly promoted the discovery of many novel possible vaccine and drug targets, as well as diagnostic biomarkers, via high-throughput and sensitive proteomics methods. In particular, immuno-proteomics approaches are essential in screening proteins from different schistosome species in both animal models and clinical sources. Moreover, protein microarray and microplate immuno-proteomics allow for unlimited virtual screening of any antigen. This includes surface-exposed hypothetical proteins from the predicted proteomes of schistosome species [172]. The advancement of new technologies, including genomics, transcriptomics, microarrays and immunomic profiling, has helped significantly in the identification of promising new schistosome target proteins, which are crucial for the survival of the parasite in the host [172].

The combination of two different proteins that interact to perform a similar function has been shown to result in higher levels of vaccine-induced protection. Targeting key biological functions of schistosomes that are critical for the survival of the parasite, such as nutrient uptake, metabolism and tegumental integrity, represent key potential sites to consider for the elimination of the schistosome through vaccination and/or chemotherapy. Although significant progress has been made in previous years in the identification of promising vaccine/drug candidates, schistosomiasis drug/vaccine development has proven highly challenging and costly; hence, many vaccine and drug candidates fail to even make it to clinical trials [149].

\section{Conclusions}

Schistosomiasis is most prevalent in resource-poor areas where farming and fishing activities are common to sustain households. As such, pharmaceutical industries do not put much effort into developing various treatment options for this disease, as it mostly affects people who cannot afford highly priced drugs and do not have access to good health care systems. For these reasons, this disease falls under the 'neglected diseases' category. It has been reported that this ailment predisposes its sufferers to bladder cancer, human papilloma virus and HIV, which all cause a high disease burden in many countries, especially in sub-Saharan Africa. This has raised concerns about a search for alternative treatment options to supplement PZQ. Targeting specific protein interactions within the schistosome is an interesting approach owing to the growing interest in the therapeutic potential of protein modulators. Although no drug has been designed by targeting PPIs in schistosomiasis, a few protein interactions have shown potential as therapeutic targets against schistosomiasis, such as Sm29 and Sm14. In addition, targeting protein interactions that have the potential to assist schistosomes in acquiring resistance against PZQ and escaping the immune defense mechanism of the host will lay a basis for anti-schistosomal drug discovery through PPIs. The oxidative stress response by the host immune defense system and incubation of schistosome worms with sub-lethal doses of PZQ lead to an increase in oxidative stress in the worm, resulting in cellular protein unfolding and aggregation in the endoplasmic reticulum, causing loss of cell viability and function in the worm. This induces the upregulation of a family of chaperone proteins, specifically the Hsp60 and Hsp10 chaperonin complex, which assists the worm to overcome the oxidative stress response and decreases its sensitivity to PZQ. An exploration of the actual mechanism by which this protein complex allows the worm to escape host immune responses will lay the ground for determination of specific protein inhibitors that can potentially modulate its function in vitro and in vivo. Inhibitors of this protein complex will not only assist in the development of new drugs, but can potentially reduce the resistance levels of schistosomes to PZQ.

The infection process in schistosomes is facilitated by the phototaxic cercariae, which move towards the surface of shallow water, where they maximize their chance of contact with humans. The cercariae follow a thermal gradient to find their potential hosts and when 
they make contact with human skin, they release chemical signals, including medium-chain fatty acids such as linoleic acid, to stimulate skin invasion. The first step in the invasion process is the release of gland contents from the acetabular gland complex of the posterior of the cercarial head, mainly $\mathrm{SmCE}$, which facilitates invasion by degrading the dermal elastin. It is, therefore, clear that SmCE plays a significant role in the initiation of infection. The identification and characterization of SmCE-specific inhibitors such as Z-AAPF-CMK and Elafin, thus, present an interesting approach to reducing schistosomal infection. On a practical level, it has been suggested that studies on protease inhibitors can advance the understanding of host-parasite interactions and lead to the identification of novel vaccine candidates and/or drug targets against schistosomes [71].

For drug design purposes, it is evident that neutrophils and other effector cells elicit an immune response using elastases to fight parasites; this presents an opportunity to study specific inhibitors that can break the interaction of Smpi56 with these elastases, specifically $\mathrm{NE}$ and pancreatic elastase. Current control efforts rely on antihelminthic treatment, but to sustain their effects, drugs must be applied repeatedly and for an indefinite period, which is costly. Moreover, reports of increased rates of re-infection after mass treatment limit strategies based on chemotherapy alone. As such, a prophylactic vaccine seems the ideal method for sustainable control of schistosomiasis, alone or in combination with the current drug. Although the vaccine development process is known to be long and costly, currently, three promising vaccine candidates for S. mansoni (Sm14, SmTSP-2 and Sm-p80) are in different stages of clinical trials. Other candidates, including Sm97, Sj97, Sm29 and SmKI-1, are also in various stages of pre-clinical trials. It is hoped that new lines of inquiry building on the findings detailed in this review will advance the understanding of host-parasite interactions and lead to the recognition of new drug targets and vaccine candidates against the schistosome parasite through specific interactions between host and parasite proteins.

Author Contributions: A.P.K. and P.M. conceived the research idea; N.K.Q. wrote the original draft of the paper; P.M. developed the models in the paper; P.M. and A.P.K. critically revised the original draft before submission of the final copy of the paper. All authors have read and agreed to the published version of the manuscript.

Funding: This research received no external funding.

Institutional Review Board Statement: Not Applicable.

Informed Consent Statement: Not Applicable.

Data Availability Statement: Not Applicable.

Acknowledgments: Ndibonani Kebonang Qokoyi and Priscilla Masamba would like to thank the National Research Foundation (NRF) of South Africa for a Scarce Skills Doctoral Fellowship (Grant No: MND190612446978) and Postdoctoral Research Fellowship (Grant No: 120802), respectively. Abidemi Paul Kappo is grateful to the University Research Committee [45] of the University of Johannesburg for their research support.

Conflicts of Interest: The authors declare no conflict of interest.

\section{References}

1. Ran, X.; Gestwicki, J.E. Inhibitors of protein-protein interactions (PPIs): An analysis of scaffold choices and buried surface area. Curr. Opin. Chem. Biol. 2018, 44, 75-86. [CrossRef] [PubMed]

2. McManus, D.P.; Loukas, A. Current status of vaccines for schistosomiasis. Clin. Microbiol. Rev. 2008, 21, 225-242. [CrossRef] [PubMed]

3. Salari, P.; Fürst, T.; Knopp, S.; Utzinger, J.; Tediosi, F. Cost of interventions to control schistosomiasis: A systematic review of the literature. PLoS Negl. Trop. Dis. 2020, 14, e0008098. [CrossRef] [PubMed]

4. Colley, D.G.; Bustinduy, A.L.; Secor, W.E.; King, C.H. Human schistosomiasis. Lancet 2014, 383, 2253-2264. [CrossRef]

5. Bear, J.W.; Long, T.; Skinner, D.; McKerrow, J.H. Predictions of novel Schistosoma mansoni-human protein interactions consistent with experimental data. Sci. Rep. 2018, 8, 1-14.

6. $\quad$ Becker, J.M.; Ganatra, A.A.; Kandie, F.; Mühlbauer, L.; Ahlheim, J.; Brack, W.; Torto, B.; Agola, E.L.; McOdimba, F.; Hollert, H. Pesticide pollution in freshwater paves the way for schistosomiasis transmission. Sci. Rep. 2020, 10, 1-13. [CrossRef] 
7. Oyinloye, B.E.; Adenowo, A.F.; Kappo, A.P. Reactive oxygen species, apoptosis, antimicrobial peptides and human inflammatory diseases. Pharmaceuticals 2015, 8, 151-175. [CrossRef] [PubMed]

8. Xiao, Q.; Yu, H.; Zhu, X. The associations of hub gene polymorphisms in PI3K/AKT/mTOR pathway and Schistosomiasis Japonica infection and hepatic fibrosis. Infect. Genet. Evol. 2020, 85, 104423. [CrossRef]

9. Gryseels, B.; Polman, K.; Clerinx, J.; Kestens, L. Human schistosomiasis. Lancet 2006, 368, 1106-1118. [CrossRef]

10. Adenowo, A.F.; Oyinloye, B.E.; Ogunyinka, B.I.; Kappo, A.P. Impact of human schistosomiasis in sub-Saharan Africa. Braz. J. Infect. Dis. 2015, 19, 196-205. [CrossRef] [PubMed]

11. Aruleba, R.T.; Adekiya, T.A.; Oyinloye, B.E.; Masamba, P.; Mbatha, L.S.; Pretorius, A.; Kappo, A.P. PZQ therapy: How close are we in the development of effective alternative anti-schistosomal drugs? Infect. Disord. Drug Targets 2019, 19, 337-349. [CrossRef] [PubMed]

12. Aragon, A.D.; Imani, R.A.; Blackburn, V.R.; Cupit, P.M.; Melman, S.D.; Goronga, T.; Webb, T.; Loker, E.S.; Cunningham, C. Towards an understanding of the mechanism of action of praziquantel. Mol. Biochem. Parasitol. 2009, 164, 57-65. [CrossRef] [PubMed]

13. Da Paixão Siqueira, L.; Fontes, D.A.F.; Aguilera, C.S.B.; Timóteo, T.R.R.; Ângelos, M.A.; Silva, L.C.P.B.B.; de Melo, C.G.; Rolim, L.A.; da Silva, R.M.F.; Neto, P.J.R. Schistosomiasis: Drugs used and treatment strategies. Acta Trop. 2017, 176, 179-187. [CrossRef] [PubMed]

14. Cioli, D.; Pica-Mattoccia, L.; Basso, A.; Guidi, A. Schistosomiasis control: Praziquantel forever? Mol. Biochem. Parasitol. 2014, 195, 23-29. [CrossRef]

15. Utzinger, J.; Keiser, J. Schistosomiasis and soil-transmitted helminthiasis: Common drugs for treatment and control. Expert Opin. Pharmacother. 2004, 5, 263-285. [CrossRef]

16. Melman, S.D.; Steinauer, M.L.; Cunningham, C.; Kubatko, L.S.; Mwangi, I.N.; Wynn, N.B.; Mutuku, M.W.; Karanja, D.M.; Colley, D.G.; Black, C.L. Reduced susceptibility to praziquantel among naturally occurring Kenyan isolates of Schistosoma mansoni. PLoS Negl. Trop. Dis. 2009, 3, e504. [CrossRef] [PubMed]

17. Lyu, H.; Petukhov, P.A.; Banta, P.R.; Jadhav, A.; Lea, W.A.; Cheng, Q.; Arnér, E.S.; Simeonov, A.; Thatcher, G.R.; Angelucci, F. Characterization of lead compounds targeting the selenoprotein thioredoxin glutathione reductase for treatment of schistosomiasis. ACS Infect. Dis. 2020, 6, 393-405. [CrossRef]

18. Calixto, N.M.; Dos Santos, D.B.; Bezerra, J.C.B.; Silva, L.D.A. In silico repositioning of approved drugs against Schistosoma mansoni energy metabolism targets. PLoS ONE 2018, 13, e0203340. [CrossRef]

19. Fogarty, C.E.; Zhao, M.; McManus, D.P.; Duke, M.G.; Cummins, S.F.; Wang, T. Comparative study of excretory-secretory proteins released by Schistosoma mansoni-resistant, susceptible and naïve Biomphalaria glabrata. Parasites Vectors 2019, 12, 1-17. [CrossRef]

20. Cuesta-Astroz, Y.; de Oliveira, F.S.; Nahum, L.A.; Oliveira, G. Helminth secretomes reflect different lifestyles and parasitized hosts. Int. J. Parasitol. 2017, 47, 529-544. [CrossRef]

21. Cuesta-Astroz, Y.; Santos, A.; Oliveira, G.; Jensen, L.J. Analysis of predicted host-parasite interactomes reveals commonalities and specificities related to parasitic lifestyle and tissues tropism. Front. Immunol. 2019, 10, 212. [CrossRef]

22. Sotillo, J.; Pearson, M.S.; Becker, L.; Mekonnen, G.G.; Amoah, A.S.; Van Dam, G.; Corstjens, P.L.; Murray, J.; Mduluza, T.; Mutapi, F. In-depth proteomic characterization of Schistosoma haematobium: Towards the development of new tools for elimination. PLoS Negl.Trop. Dis. 2019, 13, e0007362. [CrossRef]

23. Abouel-Nour, M.F.; Lotfy, M.; Attallah, A.M.; Doughty, B.L. Schistosoma mansoni major egg antigen Smp40: Molecular modeling and potential immunoreactivity for anti-pathology vaccine development. Mem. Inst. Oswaldo Cruz 2006, 101, 365-372. [CrossRef] [PubMed]

24. Roger, E.; Grunau, C.; Pierce, R.J.; Hirai, H.; Gourbal, B.; Galinier, R.; Emans, R.; Cesari, I.M.; Cosseau, C.; Mitta, G. Controlled chaos of polymorphic mucins in a metazoan parasite (Schistosoma mansoni) interacting with its invertebrate host (Biomphalaria glabrata). PLoS Negl.Trop. Dis. 2008, 2, e330. [CrossRef] [PubMed]

25. Haeberlein, S.; Obieglo, K.; Ozir-Fazalalikhan, A.; Chayé, M.A.; Veninga, H.; van der Vlugt, L.E.; Voskamp, A.; Boon, L.; den Haan, J.M.; Westerhof, L.B. Schistosome egg antigens, including the glycoprotein IPSE/alpha-1, trigger the development of regulatory B cells. PLoS Pathog. 2017, 13, e1006539. [CrossRef] [PubMed]

26. Mathieson, W.; Wilson, R.A. A comparative proteomic study of the undeveloped and developed Schistosoma mansoni egg and its contents: The miracidium, hatch fluid and secretions. Int. J. Parasitol. 2010, 40, 617-628. [CrossRef]

27. Ludolf, F.; Patrocínio, P.R.; Corrêa-Oliveira, R.; Gazzinelli, A.; Falcone, F.H.; Teixeira-Ferreira, A.; Perales, J.; Oliveira, G.C.; Silva-Pereira, R.A. Serological screening of the Schistosoma mansoni adult worm proteome. PLoS Negl. Trop. Dis. 2014,8, e2745. [CrossRef]

28. Nakamoto, H.; Vigh, L. The small heat shock proteins and their clients. Cell. Mol. Life Sci. 2007, 64, 294-306. [CrossRef]

29. Wang, T.; Zhao, M.; Rotgans, B.A.; Strong, A.; Liang, D.; Ni, G.; Limpanont, Y.; Ramasoota, P.; McManus, D.P.; Cummins, S.F. Proteomic analysis of the Schistosoma mansoni miracidium. PLoS ONE 2016, 11, e0147247. [CrossRef]

30. Rao, R.V.; Bredesen, D.E. Misfolded proteins, endoplasmic reticulum stress and neurodegeneration. Curr. Opin. Cell Biol. 2004, 16, 653-662. [CrossRef] 
31. Delcroix, M.; Sajid, M.; Caffrey, C.R.; Lim, K.-C.; Dvořák, J.; Hsieh, I.; Bahgat, M.; Dissous, C.; McKerrow, J.H. A multienzyme network functions in intestinal protein digestion by a platyhelminth parasite. J. Biol. Chem. 2006, 281, 39316-39329. [CrossRef] [PubMed]

32. Stack, C.; Dalton, J.P.; Robinson, M.W. The phylogeny, structure and function of trematode cysteine proteases, with particular emphasis on the Fasciola hepatica cathepsin L family. In Cysteine Proteases of Pathogenic Organisms; Springer: Berlin/Heidelberg, Germany, 2011; pp. 116-135.

33. Zhang, T.; Mo, X.-J.; Xu, B.; Yang, Z.; Gobert, G.N.; Yan, S.; Feng, Z.; Hu, W. Enzyme activity of Schistosoma japonicum cercarial elastase SjCE-2b ascertained by in vitro refolded recombinant protein. Acta Trop. 2018, 187, 15-22. [CrossRef] [PubMed]

34. Knudsen, G.M.; Medzihradszky, K.F.; Lim, K.-C.; Hansell, E.; McKerrow, J.H. Proteomic analysis of Schistosoma mansoni cercarial secretions. Mol. Cell. Proteom. 2005, 4, 1862-1875. [CrossRef] [PubMed]

35. Abaza, S.M. Heat shock proteins and parasitic diseases: Part 1: Helminths. Parasitol. United J. 2014, 7, 93. [CrossRef]

36. Abou-El-Naga, I.F. Heat shock protein 70 (Hsp70) in Schistosoma mansoni and its role in decreased adult worm sensitivity to praziquantel. Parasitology 2020, 147, 634-642. [CrossRef]

37. Sotillo, J.; Pearson, M.; Becker, L.; Mulvenna, J.; Loukas, A. A quantitative proteomic analysis of the tegumental proteins from Schistosoma mansoni schistosomula reveals novel potential therapeutic targets. Int. J. Parasitol. 2015, 45, 505-516. [CrossRef] [PubMed]

38. Brito, C.; Caldas, I.; Coura Filho, P.; Correa-Oliveira, R.; Oliveira, S. CD4+ T cells of schistosomiasis naturally resistant individuals living in an endemic area produce interferon-gamma and tumour necrosis factor-alpha in response to the recombinant 14KDA Schistosoma mansoni fatty acid-binding protein. Scand. J. Immunol. 2000, 51, 595-601. [CrossRef]

39. Liu, F.; Cui, S.-J.; Hu, W.; Feng, Z.; Wang, Z.-Q.; Han, Z.-G. Excretory/secretory proteome of the adult developmental stage of human blood fluke, Schistosoma japonicum. Mol. Cell. Proteom. 2009, 8, 1236-1251. [CrossRef]

40. Ramajo-Hernández, A.; Pérez-Sánchez, R.; Ramajo-Martín, V.; Oleaga, A. Schistosoma bovis: Plasminogen binding in adults and the identification of plasminogen-binding proteins from the worm tegument. Exp. Parasitol. 2007, 115, 83-91. [CrossRef]

41. Horn, M.; Fajtová, P.; Arreola, L.R.; Ulrychová, L.; Bartošová-Sojková, P.; Franta, Z.; Protasio, A.V.; Opavský, D.; Vondrášek, J.; McKerrow, J.H. Trypsin-and chymotrypsin-like serine proteases in Schistosoma mansoni-'the undiscovered country'. PLoS Negl. Trop. Dis. 2014, 8, e2766. [CrossRef]

42. Cleenewerk, L.; Garssen, J.; Hogenkamp, A. Clinical use of Schistosoma mansoni antigens as novel immunotherapies for autoimmune disorders. Front. Immunol. 2020, 11, 1821. [CrossRef] [PubMed]

43. Yamamoto, H.; Fukui, N.; Adachi, M.; Saiki, E.; Yamasaki, A.; Matsumura, R.; Kuroyanagi, D.; Hongo, K.; Mizobata, T.; Kawata, Y. Human Molecular Chaperone Hsp60 and Its Apical Domain Suppress Amyloid Fibril Formation of $\alpha$-Synuclein. Int. J. Mol. Sci. 2020, 21, 47. [CrossRef] [PubMed]

44. López-Otín, C.; Bond, J.S. Proteases: Multifunctional enzymes in life and disease. J. Biol. Chem. 2008, 283, 30433. [CrossRef] [PubMed]

45. Silverman, G.A.; Bird, P.I.; Carrell, R.W.; Church, F.C.; Coughlin, P.B.; Gettins, P.G.; Irving, J.A.; Lomas, D.A.; Luke, C.J.; Moyer, R.W. The serpins are an expanding superfamily of structurally similar but functionally diverse proteins evolution, mechanism of inhibition, novel functions, and a revised nomenclature. J. Biol. Chem. 2001, 276, 33293-33296. [CrossRef] [PubMed]

46. Crowther, D.C.; Evans, D.L.; Carrell, R.W. Serpins: Implications of a mobile reactive centre. Curr. Opin. Biotechnol. 1992, 3 , 399-407. [CrossRef]

47. Rawlings, J.S.; Rennebeck, G.; Harrison, S.M.; Xi, R.; Harrison, D.A. Two Drosophila suppressors of cytokine signaling (SOCS) differentially regulate JAK and EGFR pathway activities. BMC Cell Biol. 2004, 5, 1-15. [CrossRef]

48. De Magalhães, M.T.; Mambelli, F.S.; Santos, B.P.; Morais, S.B.; Oliveira, S.C. Serine protease inhibitors containing a Kunitz domain: Their role in modulation of host inflammatory responses and parasite survival. Microbes Infect. 2018, 20, 606-609. [CrossRef]

49. Khan, M.S.; Singh, P.; Azhar, A.; Naseem, A.; Rashid, Q.; Kabir, M.A.; Jairajpuri, M.A. Serpin inhibition mechanism: A delicate balance between native metastable state and polymerization. J. Amino Acids 2011, 2011, 606797. [CrossRef]

50. Quezada, L.A.L.; McKerrow, J.H. Schistosome serine protease inhibitors: Parasite defense or homeostasis? Ann. Acad. Bras. Ciências 2011, 83, 663-672. [CrossRef]

51. Huntington, J.A. Shape-shifting serpins-advantages of a mobile mechanism. Trends Biochem. Sci 2006, 31, 427-435. [CrossRef]

52. Hopkins, P.C.; Carrell, R.W.; Stone, S.R. Effects of mutations in the hinge region of serpins. Biochemistry 1993, 32, 7650-7657. [CrossRef] [PubMed]

53. Hansell, E.; Braschi, S.; Medzihradszky, K.F.; Sajid, M.; Debnath, M.; Ingram, J.; Lim, K.; McKerrow, J.H. Proteomic analysis of skin invasion by blood fluke larvae. PLoS Negl. Trop. Dis. 2008, 2, e262. [CrossRef]

54. Soria, C.L.D.; Lee, J.; Chong, T.; Coghlan, A.; Tracey, A.; Young, M.D.; Andrews, T.; Hall, C.; Ng, B.L.; Rawlinson, K. Single-cell atlas of the first intra-mammalian developmental stage of the human parasite Schistosoma mansoni. Nat. Commun. 2020, 11, 1-16.

55. Nowacki, F.C.; Swain, M.T.; Klychnikov, O.I.; Niazi, U.; Ivens, A.; Quintana, J.F.; Hensbergen, P.J.; Hokke, C.H.; Buck, A.H.; Hoffmann, K.F. Protein and small non-coding RNA-enriched extracellular vesicles are released by the pathogenic blood fluke Schistosoma mansoni. J. Extracell. Vesicles 2015, 4, 28665. [CrossRef] [PubMed]

56. Adebayo, A.S.; Anumudu, C.I. Annotation of virulence factors in schistosomes for the development of a SchistoVir database. J. Comput. Biol. Bioinform. Res. 2013, 5, 6-14. [CrossRef] 
57. Pakchotanon, P.; Molee, P.; Nuamtanong, S.; Limpanont, Y.; Chusongsang, P.; Limsomboon, J.; Chusongsang, Y.; Maneewatchararangsri, S.; Chaisri, U.; Adisakwattana, P. Molecular characterization of serine protease inhibitor isoform 3, SmSPI, from Schistosoma mansoni. Parasitol. Res. 2016, 115, 2981-2994. [CrossRef] [PubMed]

58. Bernardes, W.P.d.O.S.; de Araújo, J.M.; Carvalho, G.B.; Alves, C.C.; de Moura Coelho, A.T.; Dutra, I.T.S.; Teixeira, S.S.F.; de Azambuja Ribeiro, R.I.M.; de Moraes Mourão, M.; da Silva-Pereira, R.A. Sm16, A Schistosoma mansoni Immunomodulatory Protein, Fails to Elicit a Protective Immune Response and Does Not Have an Essential Role in Parasite Survival in the Definitive Host. J. Immunol. Res. 2019, 2019, 6793596. [CrossRef]

59. Haas, W.; Haeberlein, S. Penetration of cercariae into the living human skin: Schistosoma mansoni vs. Trichobilharzia szidati. Parasitol. Res. 2009, 105, 1061-1066. [CrossRef]

60. Salter, J.P.; Lim, K.-C.; Hansell, E.; Hsieh, I.; McKerrow, J.H. Schistosome invasion of human skin and degradation of dermal elastin are mediated by a single serine protease. J. Biol. Chem. 2000, 275, 38667-38673. [CrossRef]

61. Fishelson, Z.; Amiri, P.; Friend, D.S.; Marikovsky, M.; Petitt, M.; Newport, G.; Mckerrow, J.H. Schistosoma mansoni: Cell-specific expression and secretion of a serine protease during development of cercariae. Exp. Parasitol. 1992, 75, 87-98. [CrossRef]

62. Wang, J.; Ortiz, C.; Fontenot, L.; Xie, Y.; Ho, W.; Mattai, S.A.; Shih, D.Q.; Koon, H.W. High circulating elafin levels are associated with Crohn's disease-associated intestinal strictures. PLoS ONE 2020, 15, e0231796. [CrossRef] [PubMed]

63. Hunt, K.K.; Wingate, H.; Yokota, T.; Liu, Y.; Mills, G.B.; Zhang, F.; Fang, B.; Su, C.-H.; Zhang, M.; Yi, M. Elafin, an inhibitor of elastase, is a prognostic indicator in breast cancer. Breast Cancer Res. 2013, 15, 1-13. [CrossRef] [PubMed]

64. White Bear, J. Predictions of Protein-Protein Interactions in Schistosoma Mansoni. Master's Thesis, UCSF, San Francisco, CA, USA, 2012.

65. Simpson, A.; Maxwell, A.; Govan, J.; Haslett, C.; Sallenave, J.-M. Elafin (elastase-specific inhibitor) has anti-microbial activity against gram-positive and gram-negative respiratory pathogens. FEBS Lett. 1999, 452, 309-313. [CrossRef]

66. Ingram, J.R.; Rafi, S.B.; Eroy-Reveles, A.A.; Ray, M.; Lambeth, L.; Hsieh, I.; Ruelas, D.; Lim, K.; Sakanari, J.; Craik, C.S. Investigation of the proteolytic functions of an expanded cercarial elastase gene family in Schistosoma mansoni. PLoS Negl. Trop. Dis. 2012, 6, e1589. [CrossRef] [PubMed]

67. Morais, S.B.; Figueiredo, B.C.; Assis, N.R.; Alvarenga, D.M.; de Magalhães, M.T.; Ferreira, R.S.; Vieira, A.T.; Menezes, G.B.; Oliveira, S.C. Schistosoma mansoni SmKI-1 serine protease inhibitor binds to elastase and impairs neutrophil function and inflammation. PLoS Pathog. 2018, 14, e1006870. [CrossRef]

68. Cascão, R.; Moura, R.A.; Perpétuo, I.; Canhão, H.; Vieira-Sousa, E.; Mourão, A.F.; Rodrigues, A.M.; Polido-Pereira, J.; Queiroz, M.V.; Rosário, H.S. Identification of a cytokine network sustaining neutrophil and Th17 activation in untreated early rheumatoid arthritis. Arthritis Res. Ther. 2010, 12, 1-8. [CrossRef]

69. Gramegna, A.; Amati, F.; Terranova, L.; Sotgiu, G.; Tarsia, P.; Miglietta, D.; Calderazzo, M.A.; Aliberti, S.; Blasi, F. Neutrophil elastase in bronchiectasis. Respir. Res. 2017, 18, 1-13. [CrossRef]

70. Freudenstein-Dan, A.; Gold, D.; Fishelson, Z. Killing of schistosomes by elastase and hydrogen peroxide: Implications for leukocyte-mediated schistosome killing. J. Parasitol. 2003, 89, 1129-1135. [CrossRef] [PubMed]

71. Ranasinghe, S.L.; Fischer, K.; Gobert, G.N.; McManus, D.P. Functional expression of a novel Kunitz type protease inhibitor from the human blood fluke Schistosoma mansoni. Parasites Vectors 2015, 8, 1-10. [CrossRef] [PubMed]

72. Ghendler, Y.; Arnon, R.; Fishelson, Z. Schistosoma mansoni: Isolation and characterization of Smpi56, a novel serine protease inhibitor. Exp. Parasitol. 1994, 78, 121-131. [CrossRef] [PubMed]

73. Macedo Soares, M.F.D.; Araujo, C.A. Helminth products as a potential therapeutic strategy for inflammatory diseases. Inflamm. Allergy-Drug Targets 2008, 7, 113-118. [CrossRef]

74. Quezada, L.A.L.; Sajid, M.; Lim, K.C.; McKerrow, J.H. A blood fluke serine protease inhibitor regulates an endogenous larval elastase. J. Biol. Chem. 2012, 287, 7074-7083. [CrossRef] [PubMed]

75. Quezada, L.A.L. Function of Macromolecular Serine Protease Inhibitors in the Human Blood Fluke Schistosoma Mansoni. Ph.D. Thesis, University of California, San Francisco, CA, USA, 2011.

76. Lim, K.-C.; Sun, E.; Bahgat, M.; Bucks, D.; Guy, R.; Hinz, R.S.; Cullander, C.; McKerrow, J.H. Blockage of skin invasion by schistosome cercariae by serine protease inhibitors. Am. J. Trop. Med. Hyg. 1999, 60, 487-492. [CrossRef] [PubMed]

77. Hernández-Goenaga, J.; López-Abán, J.; Protasio, A.V.; Vicente Santiago, B.; Del Olmo, E.; Vanegas, M.; Fernández-Soto, P.; Patarroyo, M.A.; Muro, A. Peptides derived of Kunitz-type serine protease inhibitor as potential vaccine against experimental schistosomiasis. Front. Immunol. 2019, 10, 2498. [CrossRef] [PubMed]

78. Wan, H.; Lee, K.S.; Kim, B.Y.; Zou, F.M.; Yoon, H.J.; Je, Y.H.; Li, J.; Jin, B.R. A spider-derived Kunitz-type serine protease inhibitor that acts as a plasmin inhibitor and an elastase inhibitor. PLoS ONE 2013, 8, e53343. [CrossRef]

79. Hewitson, J.P.; Grainger, J.R.; Maizels, R.M. Helminth immunoregulation: The role of parasite secreted proteins in modulating host immunity. Mol. Biochem. Parasitol. 2009, 167, 1-11. [CrossRef]

80. Van Hellemond, J.J.; Retra, K.; Brouwers, J.F.; van Balkom, B.W.; Yazdanbakhsh, M.; Shoemaker, C.B.; Tielens, A.G. Functions of the tegument of schistosomes: Clues from the proteome and lipidome. Int. J. Parasitol. 2006, 36, 691-699. [CrossRef]

81. Mebius, M.M.; van Genderen, P.J.; Urbanus, R.T.; Tielens, A.G.; de Groot, P.G.; van Hellemond, J.J. Interference with the host haemostatic system by schistosomes. PLoS Pathog. 2013, 9, e1003781. [CrossRef]

82. Gader, A.G.M.A. Tissue factor pathway inhibitor [TFPI]: A natural coagulation inhibitor and potential therapeutic agent-A review. J. Taibah Univ. Med. Sci. 2009, 4, 1-15. 
83. Wolberg, A.S.; Aleman, M.M.; Leiderman, K.; Machlus, K.R. Procoagulant activity in hemostasis and thrombosis: Virchow's triad revisited. Anesth. Analg. 2012, 114, 275. [CrossRef]

84. Cheever, A.W.; Macedonia, J.G.; Mosimann, J.E.; Cheever, E.A. Kinetics of egg production and egg excretion by Schistosoma mansoni and S. japonicum in mice infected with a single pair of worms. Am. J. Trop. Med. Hyg. 1994, 50, 281-295. [CrossRef] [PubMed]

85. File, S. Interaction of schistosome eggs with vascular endothelium. J. Parasitol. 1995, 81, 234-238. [CrossRef] [PubMed]

86. Bachler, M.; Niederwanger, C.; Hell, T.; Höfer, J.; Gerstmeyr, D.; Schenk, B.; Treml, B.; Fries, D. Influence of factor XII deficiency on activated partial thromboplastin time (aPTT) in critically ill patients. J. Thromb. Thrombolysis 2019, 48, 466-474. [CrossRef]

87. Periayah, M.H.; Halim, A.S.; Saad, A.Z.M. Mechanism action of platelets and crucial blood coagulation pathways in hemostasis. Int. J. Hematol. Oncol. Stem Cell Res. 2017, 11, 319. [PubMed]

88. Hwang, J.-H.; Lee, W.-G.; Na, B.-K.; Lee, H.-W.; Cho, S.-H.; Kim, T.-S. Identification and characterization of a serine protease inhibitor of Paragonimus westermani. Parasitol. Res. 2009, 104, 495-501. [CrossRef]

89. Molehin, A.J.; Gobert, G.N.; Mcmanus, D.P. Serine protease inhibitors of parasitic helminths. Parasitology 2012, 139, 681. [CrossRef]

90. Irving, J.A.; Pike, R.N.; Lesk, A.M.; Whisstock, J.C. Phylogeny of the serpin superfamily: Implications of patterns of amino acid conservation for structure and function. Genome Res. 2000, 10, 1845-1864. [CrossRef]

91. Van Gent, D.; Sharp, P.; Morgan, K.; Kalsheker, N. Serpins: Structure, function and molecular evolution. Int. J. Biochem. Cell Biol. 2003, 35, 1536-1547. [CrossRef]

92. Gettins, P.G. Serpin structure, mechanism, and function. Chem. Rev. 2002, 102, 4751-4804. [CrossRef]

93. McCarthy, B.J.; Worrall, D.M. Analysis of serpin inhibitory function by mutagenesis of ovalbumin and generation of chimeric ovalbumin/PAI-2 fusion proteins. J. Mol. Biol. 1997, 267, 561-569. [CrossRef]

94. Jones, M.K.; Bong, S.H.; Green, K.M.; Duke, M.; Loukas, A.; McManus, D.P. Correlative and dynamic imaging of the hatching biology of Schistosoma japonicum from eggs prepared by high pressure freezing. PLoS Negl. Trop. Dis. 2008, 2, e334. [CrossRef]

95. Ashton, P.; Harrop, R.; Shah, B.; Wilson, R. The schistosome egg: Development and secretions. Parasitology 2001, 122, 329-338. [CrossRef]

96. Jang-Lee, J.; Curwen, R.S.; Ashton, P.D.; Tissot, B.; Mathieson, W.; Panico, M.; Dell, A.; Wilson, R.A.; Haslam, S.M. Glycomics analysis of Schistosoma mansoni egg and cercarial secretions. Mol. Cell. Proteom. 2007, 6, 1485-1499. [CrossRef]

97. Molehin, A.J.; Gobert, G.N.; Driguez, P.; Mcmanus, D.P. Functional characterization of SjB10, an intracellular serpin from Schistosoma japonicum. Parasitology 2014, 141, 1746. [CrossRef] [PubMed]

98. Huang, W.; Haas, T.A.; Biesterfeldt, J.; Mankawsky, L.; Blanton, R.E.; Lee, X. Purification and crystallization of a novel membraneanchored protein: The Schistosoma haematobium serpin. Acta Crystallogr. Sect. D Biol. Crystallogr. 1999, 55, 350-352. [CrossRef] [PubMed]

99. Harder, A. Chemotherapeutic approaches to schistosomes: Current knowledge and outlook. Parasitol. Res. 2002, 88, 395-397. [CrossRef] [PubMed]

100. Bergquist, N. Schistosomiasis vaccine development: Approaches and prospects. Mem. Inst. Oswaldo Cruz 1995, 90, $221-227$. [CrossRef] [PubMed]

101. Chistulo, L.; Loverde, P.; Engels, D. Disease watch: Schistosomiasis. TDR Nat. Rev. Microbiol. 2004, 2, $12-13$.

102. Bergquist, N.R. Schistosomiasis: From risk assessment to control. Trends Parasitol. 2002, 18, 309-314. [CrossRef]

103. Smithers, S.; Hackett, F.; Braga, V.; Simpson, A. Immunoblotting identifies additional antigens recognised by mice protectively vaccinated with adult Schistosoma mansoni tegumental membranes. Parasitol. Res. 1990, 76, 454-456. [CrossRef] [PubMed]

104. Abath, F.G.; Xavier, E.M.; Allen, R.; Gomes, Y.M.; Lucena-Silva, N.; Baliza, M.; Simpson, A.J. Characterization of Sm13, a tegumental antigen of Schistosoma mansoni. Parasitol. Res. 2000, 86, 745-752. [CrossRef] [PubMed]

105. Cardoso, F.C.; Macedo, G.C.; Gava, E.; Kitten, G.T.; Mati, V.L.; de Melo, A.L.; Caliari, M.V.; Almeida, G.T.; Venancio, T.M.; Verjovski-Almeida, S. Schistosoma mansoni tegument protein Sm29 is able to induce a Th1-type of immune response and protection against parasite infection. PLoS Negl. Trop. Dis. 2008, 2, e308. [CrossRef] [PubMed]

106. Chuah, C.; Jones, M.K.; Burke, M.L.; McManus, D.P.; Gobert, G.N. Cellular and chemokine-mediated regulation in schistosomeinduced hepatic pathology. Trends Parasitol. 2014, 30, 141-150. [CrossRef]

107. Delgado, V.; McLaren, D.J. Evidence for enhancement of IgGl subclass expression in mice polyvaccinated with radiationattenuated cercariae of Schistosoma mansoni and the role of this isotype in serum-transferred immunity. Parasite Immunol. 1990, 12, 15-32. [CrossRef] [PubMed]

108. Dunne, D.; Bickle, Q.; Worth, A.B.; Richardson, B. The blocking of human antibody-dependent, eosinophil-mediated killing of Schistosoma mansoni schistosomula by monoclonal antibodies which cross-react with a polysaccharide-containing egg antigen. Parasitology 1987, 94, 269-280. [CrossRef]

109. Hagan, P.; Blumenthal, U.J.; Dunn, D.; Simpson, A.J.; Wilkins, H.A. Human IgE, IgG4 and resistance to reinfection with Schistosoma haematobium. Nature 1991, 349, 243-245. [CrossRef]

110. Gobert, G.N.; McInnes, R.; Moertel, L.; Nelson, C.; Jones, M.K.; Hu, W.; McManus, D.P. Transcriptomics tool for the human Schistosoma blood flukes using microarray gene expression profiling. Exp. Parasitol. 2006, 114, 160-172. [CrossRef]

111. Meyer, F.; Meyer, H.; Bueding, E. Lipid metabolism in the parasitic and free-living flatworms, Schistosoma mansoni and Dugesia dorotocephala. Biochim. Biophys. Acta 1970, 210, 257-266. [CrossRef]

112. Rogers, M. Do parasites express receptors for host lipoproteins? Parasitol. Today 1991, 7, 117-120. [CrossRef] 
113. Furlong, S. Unique roles for lipids in Schistosoma mansoni. Parasitol. Today 1991, 7, 59-62. [CrossRef]

114. Moser, D.; Tendler, M.; Griffiths, G.; Klinkert, M.-Q. A 14-kDa Schistosoma mansoni polypeptide is homologous to a gene family of fatty acid binding proteins. J. Biol. Chem. 1991, 266, 8447-8454. [CrossRef]

115. Tendler, M.; Brito, C.A.; Vilar, M.M.; Serra-Freire, N.; Diogo, C.M.; Almeida, M.S.; Delbem, A.; Da Silva, J.F.; Savino, W.; Garratt, R.C. A Schistosoma mansoni fatty acid-binding protein, Sm14, is the potential basis of a dual-purpose anti-helminth vaccine. Proc. Natl. Acad. Sci. USA 1996, 93, 269-273. [CrossRef] [PubMed]

116. Mossallam, S.F.; Amer, E.I.; Ewaisha, R.E.; Khalil, A.M.; Aboushleib, H.M.; Bahey-El-Din, M. Fusion protein comprised of the two schistosomal antigens, Sm14 and Sm29, provides significant protection against Schistosoma mansoni in murine infection model. BMC Infect. Dis. 2015, 15, 1-16. [CrossRef] [PubMed]

117. Masamba, P.; Adenowo, A.F.; Oyinloye, B.E.; Kappo, A.P. Universal stress proteins as new targets for environmental and therapeutic interventions of Schistosomiasis. Int. J. Environ. Res. Public Health 2016, 13, 972. [CrossRef] [PubMed]

118. Ishida, K.; Jolly, E.R. Hsp70 may be a molecular regulator of schistosome host invasion. PLoS Negl.Trop. Dis. 2016, 10, e0004986. [CrossRef]

119. Zininga, T.; Shonhai, A. Are heat shock proteins druggable candidates. Am. J. Biochem. Biotechnol 2014, 10, 211-213. [CrossRef]

120. Crellen, T.; Allan, F.; David, S.; Durrant, C.; Huckvale, T.; Holroyd, N.; Emery, A.M.; Rollinson, D.; Aanensen, D.M.; Berriman, M. Whole genome resequencing of the human parasite Schistosoma mansoni reveals population history and effects of selection. Sci. Rep. 2016, 6, 1-13. [CrossRef] [PubMed]

121. Ishida, K.; Varrecchia, M.; Knudsen, G.M.; Jolly, E.R. Immunolocalization of anti-hsf1 to the acetabular glands of infectious schistosomes suggests a non-transcriptional function for this transcriptional activator. PLoS Negl. Trop. Dis. 2014, 8, e3051. [CrossRef] [PubMed]

122. Da'Dara, A.A.; Li, C.; Yu, X.; Zheng, M.; Zhou, J.; Shollenberger, L.M.; Li, Y.-S.; Harn, D.A. Prime-boost vaccine regimen for SjTPI and SjC23 schistosome vaccines, increases efficacy in water buffalo in a field trial in China. Front. Immunol. 2019, 10, 284. [CrossRef]

123. Zahoor, Z.; Davies, A.J.; Kirk, R.S.; Rollinson, D.; Walker, A.J. Larval excretory-secretory products from the parasite Schistosoma mansoni modulate HSP70 protein expression in defence cells of its snail host, Biomphalaria glabrata. Cell Stress Chaperones 2010, 15, 639-650. [CrossRef]

124. Yang, G.; Lu, X.; Yuan, L. LncRNA: A link between RNA and cancer. Biochim. Biophys. Acta BBA Gene Regul. Mech. 2014, 1839, 1097-1109. [CrossRef] [PubMed]

125. Moser, D.; Doumbo, O.; Klinkert, M.Q. The humoral response to heat shock protein 70 in human and murine Schistosomiasis mansoni. Parasite Immunol. 1990, 12, 341-352. [CrossRef] [PubMed]

126. Ishida, K. Identifying a Role for Heat Shock Proteins in Schistosoma Mansoni. Ph.D. Thesis, Case Western Reserve University, Cleveland, OH, USA, 2017.

127. Tielens, A.G.; Vandenheuvel, J.M.; Vaneden, W. Schistosoma mansoni: An HSP60 homologue is constitutively expressed in cercariae, adults, and sporocysts. Exp. Parasitol. 1993, 77, 495-497. [CrossRef] [PubMed]

128. Adekiya, T.A.; Aruleba, R.T.; Oyinloye, B.E.; Okosun, K.O.; Kappo, A.P. The effect of climate change and the snail-Schistosome cycle in transmission and bio-control of Schistosomiasis in sub-Saharan Africa. Int. J. Environ. Res. Public Health 2020, $17,181$. [CrossRef] [PubMed]

129. Kalinda, C.; Chimbari, M.; Mukaratirwa, S. Implications of changing temperatures on the growth, fecundity and survival of intermediate host snails of schistosomiasis: A systematic review. Int. J. Environ. Res. Public Health 2017, 14, 80. [CrossRef]

130. Mangal, T.D.; Paterson, S.; Fenton, A. Predicting the impact of long-term temperature changes on the epidemiology and control of schistosomiasis: A mechanistic model. PLoS ONE 2008, 3, e1438. [CrossRef]

131. McCreesh, N.; Booth, M. The effect of increasing water temperatures on Schistosoma mansoni transmission and Biomphalaria pfeifferi population dynamics: An agent-based modelling study. PLoS ONE 2014, 9, e101462. [CrossRef]

132. Hayer-Hartl, M.; Bracher, A.; Hartl, F.U. The GroEL-GroES chaperonin machine: A nano-cage for protein folding. Trends Biochem. Sci. 2016, 41, 62-76. [CrossRef]

133. Horwich, A. Structure and Action of Molecular Chaperones. In Structural Analysis of GroEL/GroES Chaperonin-Mediated Protein Folding: Machines That Assist Protein Folding In The Cell; World Scientific Publishing: Hackensack, NJ, USA, 2016; Volume 6, p. 49.

134. Iizuka, R.; Yoshida, T.; Shomura, Y.; Miki, K.; Maruyama, T.; Odaka, M.; Yohda, M. ATP binding is critical for the conformational change from an open to closed state in archaeal group II chaperonin. J. Biol. Chem. 2003, 278, 44959-44965. [CrossRef]

135. Radons, J. The ATP-driven Hsp60 machinery: Biological and clinical implications. Curr. Immunol. Rev. 2017, 13, 19-43. [CrossRef]

136. Meng, Q.; Li, B.X.; Xiao, X. Toward developing chemical modulators of Hsp60 as potential therapeutics. Front. Mol. Biosci. 2018, 5, 35. [CrossRef] [PubMed]

137. Xavier, R.P.; Mengarda, A.C.; Silva, M.P.; Roquini, D.B.; Salvadori, M.C.; Teixeira, F.S.; Pinto, P.L.; Morais, T.R.; Ferreira, L.L.; Andricopulo, A.D. H1-antihistamines as antischistosomal drugs: In vitro and in vivo studies. Parasites Vectors 2020, 13, 1-12. [CrossRef] [PubMed]

138. Krishna, S.; Bustamante, L.; Haynes, R.K.; Staines, H.M. Artemisinins: Their growing importance in medicine. Trends Pharmacol. Sci. 2008, 29, 520-527. [CrossRef]

139. Neves, B.J.; Andrade, C.H.; Cravo, P.V. Natural products as leads in schistosome drug discovery. Molecules 2015, $20,1872-1903$. [CrossRef] 
140. Toor, J.; Turner, H.C.; Truscott, J.E.; Werkman, M.; Phillips, A.E.; Alsallaq, R.; Medley, G.F.; King, C.H.; Anderson, R.M. The design of schistosomiasis monitoring and evaluation programmes: The importance of collecting adult data to inform treatment strategies for Schistosoma mansoni. PLoS Negl.Trop. Dis. 2018, 12, e0006717. [CrossRef] [PubMed]

141. Mo, A.X.; Agosti, J.M.; Walson, J.L.; Hall, B.F.; Gordon, L. Schistosomiasis elimination strategies and potential role of a vaccine in achieving global health goals. Am. J. Trop. Med. Hyg. 2014, 90, 54-60. [CrossRef]

142. Siddiqui, A.A.; Siddiqui, S.Z. Sm-p80-based schistosomiasis vaccine: Preparation for human clinical trials. Trends Parasitol. 2017, 33, 194-201. [CrossRef] [PubMed]

143. Berditchevski, F.; Odintsova, E. Tetraspanins as regulators of protein trafficking. Traffic 2007, 8, 89-96. [CrossRef] [PubMed]

144. Charrin, S.; Jouannet, S.; Boucheix, C.; Rubinstein, E. Tetraspanins at a glance. J. Cell Sci. 2014, 127, 3641-3648. [CrossRef]

145. Tran, M.H.; Pearson, M.S.; Bethony, J.M.; Smyth, D.J.; Jones, M.K.; Duke, M.; Don, T.A.; McManus, D.P.; Correa-Oliveira, R.; Loukas, A. Tetraspanins on the surface of Schistosoma mansoni are protective antigens against schistosomiasis. Nat. Med. 2006, 12, 835-840. [CrossRef]

146. Diab, T.; Aly, I. PP-188 efficacy of Schistosoma mansoni Paramyosin (Sm97) and fatty acid binding protein (Sm-FABP) as a candidate vaccine against schistosomiasis mansoni. Int. J. Infect. Dis. 2011, 15, S97. [CrossRef]

147. Eyayu, T.; Zeleke, A.J.; Worku, L. Current status and future prospects of protein vaccine candidates against Schistosoma mansoni infection. Parasite Epidemiol. Control 2020, 11, e00176. [CrossRef] [PubMed]

148. Tebeje, B.M.; Harvie, M.; You, H.; Loukas, A.; McManus, D.P. Schistosomiasis vaccines: Where do we stand? Parasites Vectors 2016, 9, 1-15. [CrossRef] [PubMed]

149. Sher, A.; Hall, B.; Vadas, M. Acquisition of murine major histocompatibility complex gene products by schistosomula of Schistosoma mansoni. J. Exp. Med. 1978, 148, 46-57. [CrossRef] [PubMed]

150. Ramirez, B.L.; Kurtis, J.D.; Wiest, P.M.; Arias, P.; Aligui, F.; Acosta, L.; Peters, P.; Olds, G.R. Paramyosin: A candidate vaccine antigen against Schistosoma japonicum. Parasite Immunol. 1996, 18, 49-52. [CrossRef] [PubMed]

151. Jiz, M.A.; Wu, H.; Olveda, R.; Jarilla, B.; Kurtis, J.D. Development of paramyosin as a vaccine candidate for schistosomiasis. Front. Immunol. 2015, 6, 347. [CrossRef]

152. Leenstra, T.; Acosta, L.P.; Wu, H.-W.; Langdon, G.C.; Solomon, J.S.; Manalo, D.L.; Su, L.; Jiz, M.; Jarilla, B.; Pablo, A.O. T-helper-2 cytokine responses to Sj97 predict resistance to reinfection with Schistosoma japonicum. Infect. Immun. 2006, 74, 370-381. [CrossRef]

153. Karmakar, S.; Zhang, W.; Ahmad, G.; Torben, W.; Alam, M.U.; Le, L.; Damian, R.T.; Wolf, R.F.; White, G.L.; Carey, D.W. Crossspecies protection: Schistosoma mansoni Sm-p80 vaccine confers protection against Schistosoma haematobium in hamsters and baboons. Vaccine 2014, 32, 1296-1303. [CrossRef]

154. Ahmad, G.; Zhang, W.; Torben, W.; Haskins, C.; Diggs, S.; Noor, Z.; Le, L.; Siddiqui, A.A. Prime-boost and recombinant protein vaccination strategies using Sm-p80 protects against Schistosoma mansoni infection in the mouse model to levels previously attainable only by the irradiated cercarial vaccine. Parasitol. Res. 2009, 105, 1767-1777. [CrossRef]

155. Ahmad, G.; Zhang, W.; Torben, W.; Noor, Z.; Siddiqui, A.A. Protective effects of Sm-p80 in the presence of resiquimod as an adjuvant against challenge infection with Schistosoma mansoni in mice. Int. J. Infect. Dis. 2010, 14, e781-e787. [CrossRef]

156. Ahmad, G.; Zhang, W.; Torben, W.; Ahrorov, A.; Damian, R.T.; Wolf, R.F.; White, G.L.; Carey, D.W.; Mwinzi, P.N.; Ganley-Leal, L. Preclinical prophylactic efficacy testing of Sm-p80-based vaccine in a nonhuman primate model of Schistosoma mansoni infection and immunoglobulin $\mathrm{G}$ and E responses to Sm-p80 in human serum samples from an area where Schistosomiasis is endemic. J. Infect. Dis. 2011, 204, 1437-1449. [CrossRef] [PubMed]

157. Zhang, W.; Ahmad, G.; Torben, W.; Noor, Z.; Le, L.; Damian, R.T.; Wolf, R.F.; White, G.L.; Chavez-Suarez, M.; Podesta, R.B. Sm-p80-Based DNA Vaccine Provides Baboons with Levels of Protection against Schistosoma mansoni Infection Comparable to Those Achieved by the Irradiated Cercarial Vaccine. J. Infect. Dis. 2010, 201, 1105-1112. [CrossRef]

158. Zhang, W.; Ahmad, G.; Le, L.; Rojo, J.U.; Karmakar, S.; Tillery, K.A.; Torben, W.; Damian, R.T.; Wolf, R.F.; White, G.L. Longevity of Sm-p80-specific antibody responses following vaccination with Sm-p80 vaccine in mice and baboons and transplacental transfer of Sm-p80-specific antibodies in a baboon. Parasitol. Res. 2014, 113, 2239-2250. [CrossRef] [PubMed]

159. Alves, C.C.; Araujo, N.; dos Santos, V.C.F.; Couto, F.B.; Assis, N.R.; Morais, S.B.; Oliveira, S.C.; Fonseca, C.T. Sm29, but not Sm22. 6 retains its ability to induce a protective immune response in mice previously exposed to a Schistosoma mansoni infection. PLoS Negl.Trop. Dis. 2015, 9, e0003537. [CrossRef] [PubMed]

160. Alves, C.C.; Araujo, N.; Bernardes, W.P.d.O.S.; Mendes, M.M.; Oliveira, S.C.; Fonseca, C.T. A Strong humoral immune response induced by a vaccine formulation containing $\mathrm{rSm} 29$ adsorbed to alum is associated with protection against Schistosoma mansoni reinfection in mice. Front. Immunol. 2018, 9, 2488. [CrossRef] [PubMed]

161. Pinheiro, C.S.; Ribeiro, A.P.D.; Cardoso, F.C.; Martins, V.P.; Figueiredo, B.C.; Assis, N.R.; Morais, S.B.; Caliari, M.V.; Loukas, A.; Oliveira, S.C. A multivalent chimeric vaccine composed of S chistosoma mansoni Sm TSP-2 and Sm29 was able to induce protection against infection in mice. Parasite Immunol. 2014, 36, 303-312. [CrossRef] [PubMed]

162. Tendler, M.; Simpson, A.J. The biotechnology-value chain: Development of Sm14 as a schistosomiasis vaccine. Acta Trop. 2008, 108, 263-266. [CrossRef]

163. Santini-Oliveira, M.; Coler, R.N.; Parra, J.; Veloso, V.; Jayashankar, L.; Pinto, P.M.; Ciol, M.A.; Bergquist, R.; Reed, S.G.; Tendler, M. Schistosomiasis vaccine candidate Sm14/GLA-SE: Phase 1 safety and immunogenicity clinical trial in healthy, male adults. Vaccine 2016, 34, 586-594. [CrossRef] 
164. Tendler, M.; Almeida, M.; Simpson, A. Development of the Brazilian anti schistosomiasis vaccine based on the recombinant fatty acid binding protein Sm14 plus GLA-SE adjuvant. Front. Immunol. 2015, 6, 218. [CrossRef]

165. Ranasinghe, S.L.; Duke, M.; Harvie, M.; McManus, D.P. Kunitz-type protease inhibitor as a vaccine candidate against schistosomiasis mansoni. Int. J. Infect. Dis. 2018, 66, 26-32. [CrossRef]

166. Noya, O.; de Noya, B.A.; Guzmán, F.; Bermúdez, H. Immunogenicity of Sm32 synthetic peptides derived from the Schistosoma mansoni adult worm. Immunol. Lett. 2003, 88, 211-219. [CrossRef]

167. Chacon, N.; Losada, S.; Bermudez, H.; Cesari, I.; Hoebeke, J.; Noya, O. Immunogenicity of polymerizable synthetic peptides derived from a vaccine candidate against schistosomiasis: The asparaginyl endopeptidase (Sm32). Immunol. Lett. 2003, 88, 199-210. [CrossRef]

168. Dalton, J.; Clough, K.; Jones, M.; Brindley, P. The cysteine proteinases of Schistosoma mansoni cercariae. Parasitology 1997, 114, 105-112. [CrossRef]

169. Chlichlia, K.; Bahgat, M.; Ruppel, A.; Schirrmacher, V. DNA vaccination with asparaginyl endopeptidase (Sm32) from the parasite Schistosoma mansoni: Anti-fecundity effect induced in mice. Vaccine 2001, 20, 439-447. [CrossRef]

170. Molehin, A.J.; Rojo, J.U.; Siddiqui, S.Z.; Gray, S.A.; Carter, D.; Siddiqui, A.A. Development of a schistosomiasis vaccine. Expert Rev. Vaccines 2016, 15, 619-627. [CrossRef] [PubMed]

171. Driguez, P.; McManus, D.P.; Gobert, G.N. Clinical implications of recent findings in schistosome proteomics. Expert Rev. Proteom. 2016, 13, 19-33. [CrossRef] [PubMed]

172. Merrifield, M.; Hotez, P.J.; Beaumier, C.M.; Gillespie, P.; Strych, U.; Hayward, T.; Bottazzi, M.E. Advancing a vaccine to prevent human schistosomiasis. Vaccine 2016, 34, 2988-2991. [CrossRef] [PubMed] 